University of South Florida

DIGITAL COMMONS

Digital Commons @ University of

@ UNIVERSITY OF SOUTH FLORIDA

South Florida

2-1-1998

\title{
Tropical Instability Wave Energetics: Observations from the Tropical Instability Wave Experiment
}

L. Qiao

University of South Florida

Robert $\mathrm{H}$. Weisberg

University of South Florida, weisberg@marine.usf.edu

Follow this and additional works at: https://digitalcommons.usf.edu/msc_facpub

Part of the Marine Biology Commons

\section{Scholar Commons Citation}

Qiao, L. and Weisberg, Robert H., "Tropical Instability Wave Energetics: Observations from the Tropical Instability Wave Experiment" (1998). Marine Science Faculty Publications. 148.

https://digitalcommons.usf.edu/msc_facpub/148

This Article is brought to you for free and open access by the College of Marine Science at Digital Commons @ University of South Florida. It has been accepted for inclusion in Marine Science Faculty Publications by an authorized administrator of Digital Commons @ University of South Florida. For more information, please contact digitalcommons@usf.edu. 


\title{
Tropical Instability Wave Energetics: Observations from the Tropical Instability Wave Experiment
}

\author{
L. QIAO AND R. H. WeISBERG \\ Department of Marine Science, University of South Florida, St. Petersburg, Florida \\ (Manuscript received 24 July 1996, in final form 20 June 1997)
}

ABSTRACT

\begin{abstract}
Ocean velocity data from an array of subsurface moorings deployed from May 1990 to June 1991 during the Tropical Instability Wave Experiment are used to study the energetics of planetary waves in the vicinity of the equator at $140^{\circ} \mathrm{W}$. Such waves, observed from August to December 1990, were initiated by barotropic instability arising primarily from the cyclonic shear region of the South Equatorial Current and Equatorial Undercurrent just north of the equator. Subsequently, local barotropic production continued to maintain and modulate these tropical instability waves through a combination of cyclonic shear and meridional velocity component divergence just north of the equator. The end of the wave season coincided with the propagation past the array of a large intraseasonal Kelvin wave.
\end{abstract}

\section{Introduction}

The Tropical Instability Wave Experiment (TIWE), conducted in the central Pacific in 1990, was designed to further our understanding of tropical ocean, planetary scale waves that result from instability of the large-scale zonally oriented currents. Qiao and Weisberg (1995) reviews observations of tropical instability waves, describes the TIWE equatorial array measurements, and discusses the kinematics of the waves observed in 1990. The instability waves during TIWE were found to be narrowband in both frequency and zonal wavenumber, with central period, zonal wavelength, and westward phase propagation estimated to be $500 \mathrm{~h}, 1060 \mathrm{~km}$, and $59 \mathrm{~cm} \mathrm{~s}^{-1}$. The distribution of amplitude showed a welldefined wave season lasting from August to December 1990, with wave amplitude confined primarily to the near surface region above the Equatorial Undercurrent (EUC) core with maximum values on the equator (Fig. $1)$. The onset of the wave season coincided with the acceleration of the South Equatorial Current (SEC) and the termination coincided with a strong eastward momentum pulse propagating from the west as a Kelvin wave. Particle motions in the horizontal plane were described by eccentric ellipses oriented toward the north, but tilting into the cyclonic shear of the SEC. The tilt was maximum near the surface, just north of the equator, and it decreased to the south and with depth.

Corresponding author address: Dr. Robert H. Weisberg, Department of Marine Science, University of South Florida, 140 Seventh Avenue South, St. Petersburg, FL 33701-5016.

E-mail: weisberg@marine.usf.edu
This paper now examines the energetics of these waves as observed during TIWE. Previous studies found that the seasonally modulated instability waves are related to the westward flowing SEC, which is further associated with the intensity of the southeast trade winds and the zonal pressure gradient tending to balance these winds [e.g., Halpern et al. (1988) for the Pacific and Weisberg and Weingartner (1988) for the Atlantic]. These studies suggest that the instability waves interact directly with the background fields and are modulated by processes that control the background fields. For example, Weisberg (1984), using moored current meters in the Atlantic, and Hansen and Paul (1984), using surface drifters in the Pacific, both reported large horizontal Reynolds stress within the SEC. Weisberg (1984) found that the onset of the horizontal Reynolds stress occurred synchronously with instability waves and that the deformation work (barotropic conversion) calculated within the surface cyclonic shear region of the SEC just north of the equator was sufficient to account for the wave's growth. Hansen and Paul (1984) also showed that the waves extract energy from the mean flow just to the north of and, conversely, just to the south of the equator. The Reynolds stress analyses of Lukas (1987) and Wilson and Leetmaa (1988) provide further support for near-surface barotropic production just north of the equator.

Weisberg and Weingartner (1988) investigated the EP (Eliassen and Palm 1960) flux vector divergence between the equator and $0.75^{\circ} \mathrm{N}$ and $0.75^{\circ} \mathrm{S}$, the energy balance on the equator, and the distributions of the Reynolds fluxes off the equator at $1.75^{\circ} \mathrm{N}, 3^{\circ} \mathrm{N}$, and $6^{\circ} \mathrm{N}$ and concluded that the instability waves in the Atlantic 
a.

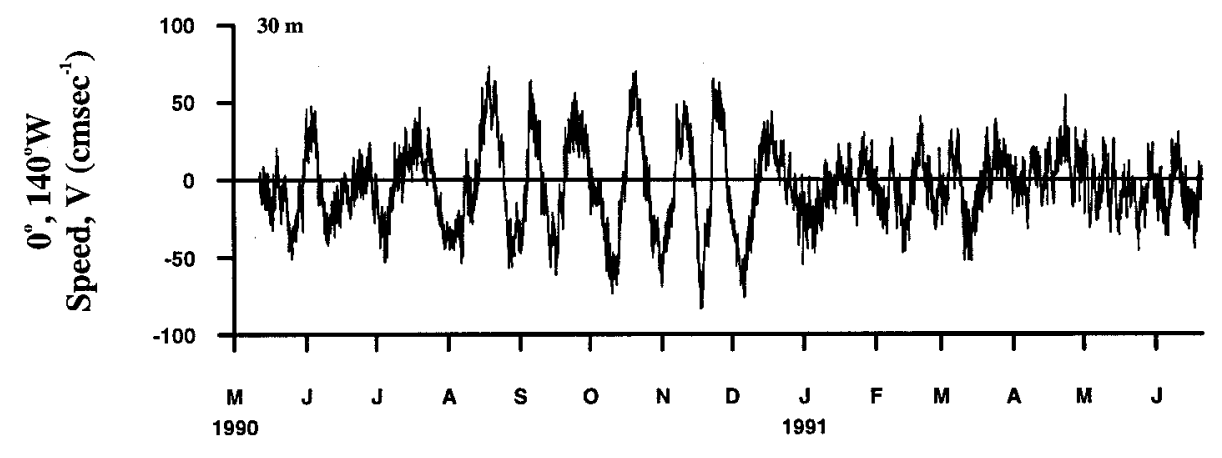

b.
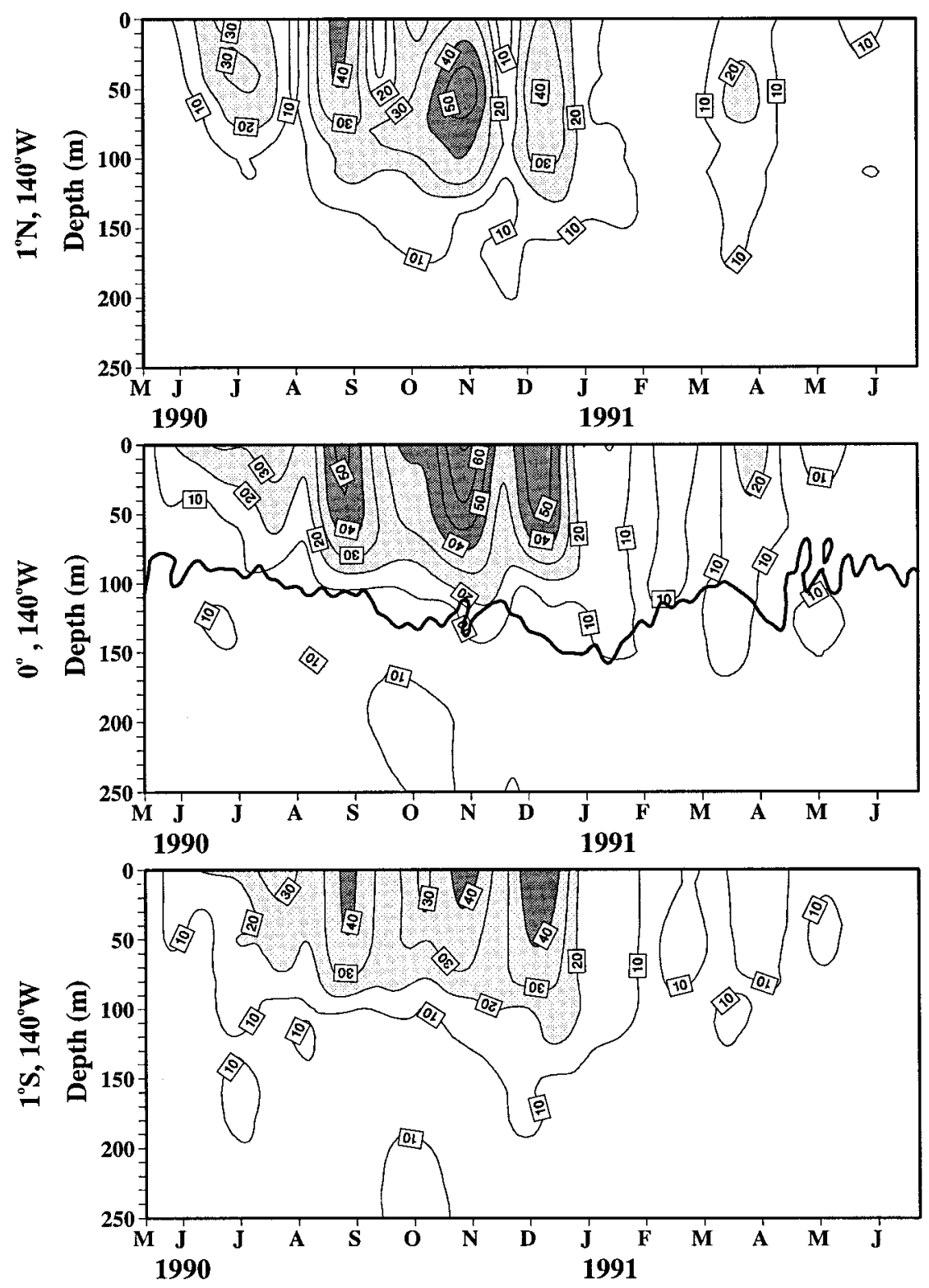
gain their energy through barotropic instability within the cyclonic shear region of the SEC just north of the equator. Luther and Johnson (1990) analyzed the energy budget using repeated meridional sections of velocity and density from the Hawaii to Tahiti Shuttle Experiment and identified three distinct sources of wave energy, each occurring at different times of the year. The first is the barotropic mechanism described earlier, but with emphasis on the shear region between the EUC at the equator and the SEC north of the equator, occurring in boreal summer/fall; the other two are baroclinic mechanisms occurring at the frontal regions between $3^{\circ} \mathrm{N}$ and $6^{\circ} \mathrm{N}$ in winter and at $5^{\circ} \mathrm{N}-9^{\circ} \mathrm{N}$ in spring, respectively.

Wavelike oscillations of the zonal equatorial currents reported from numerical model simulations (e.g., Philander et al. 1986) show remarkable agreement with observations. Numerical models have also been useful for studying the mechanisms and the regions of generation of the instability waves. The stability analysis of Cox (1980) demonstrated the importance of barotropic instability due to the shear of the mean surface currents in general, and studies by McCreary and Yu (1992) and Yu et al. (1995) have clarified the importance of the cyclonic shear region of the combined SEC and EUC contrasted with the relative unimportance of the North Equatorial Countercurrent (NECC). They also introduced a new frontal instability mechanism related to the strong meridional gradient in the sea surface temperature (SST) north of the equator and suggested that this SST front is an essential part of the tropical instability wave dynamics. Proehl (1996) discussed tropical instability waves in terms of wave overreflection and, since this process depends on both the mean density and current structures, it was suggested that the classification of the wave energy source may be difficult.

Using current velocity data from the TIWE equatorial array and temperature data (for estimating density and the meridional pressure gradient) from the Tropical Ocean Global Atmosphere Tropical Atmosphere Ocean (TOGA TAO) array, examination of the tropical instability wave energetics is now made by analyzing the perturbation energy equations. Section 2 describes the evolution of the perturbation kinetic and potential energies, term by term, and section 3 discusses and summarizes the results.

\section{Perturbation energies}

The perturbation energy includes both kinetic and potential energy contributions. The perturbation kinetic energy (PKE) equation follows directly from the momentum equations (the appendix):

$$
\begin{aligned}
(\mathrm{PKE})_{t}= & -(U \mathrm{PKE})_{x}-(V \mathrm{PKE})_{y}-(W \mathrm{PKE})_{z} \\
& -\left\langle u^{\prime} u^{\prime}\right\rangle U_{x}-\left\langle u^{\prime} v^{\prime}\right\rangle\left(U_{y}+V_{x}\right) \\
& -\left\langle v^{\prime} v^{\prime}\right\rangle V_{y}-\left\langle u^{\prime} w^{\prime}\right\rangle U_{z}-\left\langle v^{\prime} w^{\prime}\right\rangle V_{z} \\
& -\frac{1}{2}\left\langle\left(u^{\prime 2}+v^{\prime 2}\right) u^{\prime}\right\rangle_{x}-\frac{1}{2}\left\langle\left(u^{\prime 2}+v^{\prime 2}\right) v^{\prime}\right\rangle_{y} \\
& -\frac{1}{2}\left\langle\left(u^{\prime 2}+v^{\prime 2}\right) w^{\prime}\right\rangle_{z} \\
& -\left(\left\langle p_{x}^{\prime} u^{\prime}\right\rangle+\left\langle p_{y}^{\prime} v^{\prime}\right\rangle+\left\langle p_{z}^{\prime} w^{\prime}\right\rangle\right) \\
& +g\left\langle\rho^{\prime} w^{\prime}\right\rangle,
\end{aligned}
$$

where PKE $=\bar{\rho}\left\langle u^{\prime 2}+v^{\prime 2}\right\rangle / 2 ;(u, v, w)$ are the velocity components in a conventional Cartesian coordinate system with $(x, y, z)$ directed positive to the east, north, and up, respectively; subscripted variables denote partial differentiation; angle brackets (or an overbar) denote time averages as running means; and primes denote deviations of the individual variables about their running means, which are denoted by capitalized variables. Consistent with the finding of Qiao and Weisberg (1995) that the instability waves observed during TIWE had a central periodicity of $500 \mathrm{~h}, 500 \mathrm{~h}$ is chosen as the basic time interval for computing running means. Each line on the right-hand side of Eq. (1) has a specific physical meaning: (1a) is the divergence of the PKE by the mean flow; (1b) gives the barotropic energy conversion between the mean and the perturbation flow fields through deformation work; (1c) represents the divergence of the PKE by the perturbation velocity field; (1d) is the pressure work divergence that tends to redistribute the PKE spatially; and (1e) is the energy conversion between the PKE and the perturbation potential energy (PPE). To examine the processes that control the growth and decay of the PKE, the terms on the right-hand side of the PKE equation are estimated. Positive (negative) values act to increase (decrease) the PKE.

The PPE equation follows from the perturbation density equation (the appendix)

$$
\begin{aligned}
(\mathrm{PPE})_{t}= & -U(\mathrm{PPE})_{x}-V(\mathrm{PPE})_{y}-W(\mathrm{PPE})_{z} \\
& -g\left(\bar{\rho}_{x}\left\langle\rho^{\prime} u^{\prime}\right\rangle-g \bar{\rho}_{y}\left\langle\rho^{\prime} v^{\prime}\right\rangle\right) / \bar{\rho}_{z} \\
& -\frac{1}{2} g\left(\left\langle\rho_{x}^{\prime 2} u^{\prime}\right\rangle+\left\langle\rho_{y}^{\prime 2} v^{\prime}\right\rangle+\left\langle\rho_{z}^{\prime 2} w^{\prime}\right\rangle\right) / \bar{\rho}_{z} \\
& -g\left\langle\rho^{\prime} w^{\prime}\right\rangle,
\end{aligned}
$$

$\leftarrow$

FIG. 1. (a) Time series of the hourly sampled $v$ component at $30-\mathrm{m}$ depth from the mooring located at $0^{\circ}$, $140^{\circ} \mathrm{W}$, and (b) the complex demodulation amplitude for the $v$ component as a function of depth and time at $1^{\circ} \mathrm{N}, 140^{\circ} \mathrm{W}$ computed over a $1.58 \times 10^{-3} \mathrm{cph}$ bandwidth centered on $2.00 \times 10^{-3} \mathrm{cph}$. Stippling highlights regions with amplitudes greater than $20 \mathrm{~cm} \mathrm{~s}^{-1}$. 

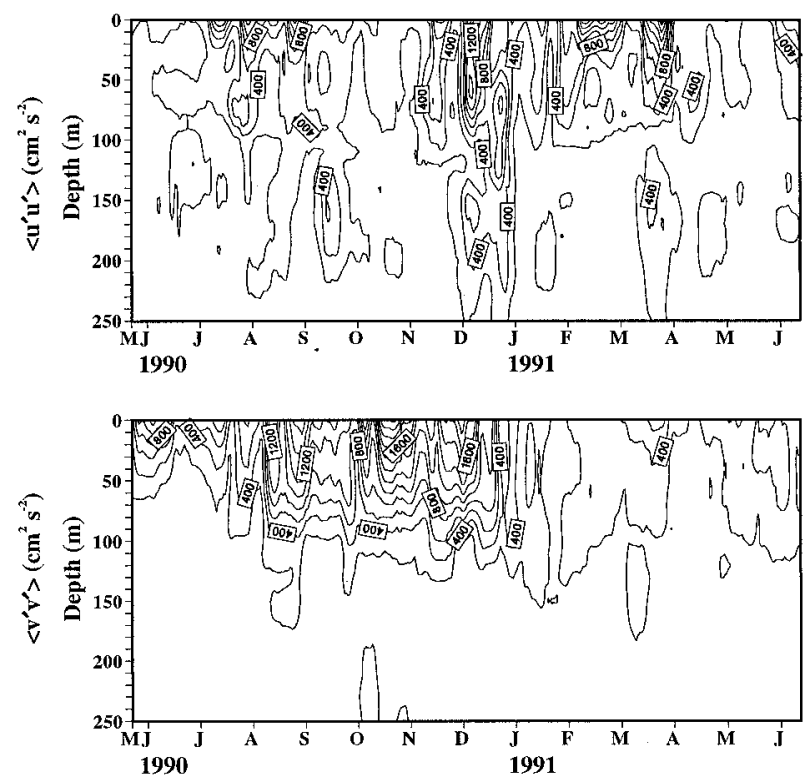

FIG. 2. Reynolds stress components $\left\langle u^{\prime} u^{\prime}\right\rangle$ and $\left\langle v^{\prime} v^{\prime}\right\rangle$ as functions of time and depth at $0^{\circ}, 140^{\circ} \mathrm{W}$. The contour interval is $200 \mathrm{~cm}^{2} \mathrm{~s}^{-2}$.

where PPE $=(1 / 2) g\left\langle\rho^{\prime 2}\right\rangle / \bar{\rho}_{z}$. On the right-hand side: $(2 \mathrm{a})$ is the mean advection of the PPE; (2b) is the baroclinic energy conversion between the mean density field and the perturbations; (2c) is the advection of the PPE by the perturbation velocity; and (2d) is the conversion between PKE and PPE. Generally, if $g\left\langle\rho^{\prime} w^{\prime}\right\rangle$ is small, then the net influence of the PPE on the PKE is small, and a detailed examination of PPE is not necessary. An examination of both the PKE and the PPE is presented below. Central differences were generally applied in evaluating the spatial differential operators in the PKE and PPE equations. To reveal the temporal and vertical variations of the relevant quantities in Eqs. (1) and (2) the format for presentation will consist of isopleth contours for each term as a function of time and depth at each location where estimates can be made.

\section{a. Perturbation kinetic energy}

\section{1) Reynolds STREsS TENSOR AND ReynOlds DENSITY FLUX}

It is useful to look at the distribution of the Reynolds stress tensor and the Reynolds density flux before comparing each of the terms in the PKE and PPE equations. The two diagonal components $\left\langle u^{\prime} u^{\prime}\right\rangle$ and $\left\langle v^{\prime} v^{\prime}\right\rangle$ at $0^{\circ}$, $140^{\circ} \mathrm{W}$ are shown in Fig. 2. They have the same structures as the complex demodulation amplitudes for the zonal and the meridional velocity components at $0^{\circ}$, $140^{\circ} \mathrm{W}$ respectively (Figs. 9 and 10 of Qiao and Weisberg 1995). Vertically, large Reynolds stress values are generally confined to above $110 \mathrm{~m}$ (the record-length average depth of the EUC core) with maxima typically at the surface. Temporally, $\left\langle\boldsymbol{v}^{\prime} \boldsymbol{v}^{\prime}\right\rangle$ is large only from
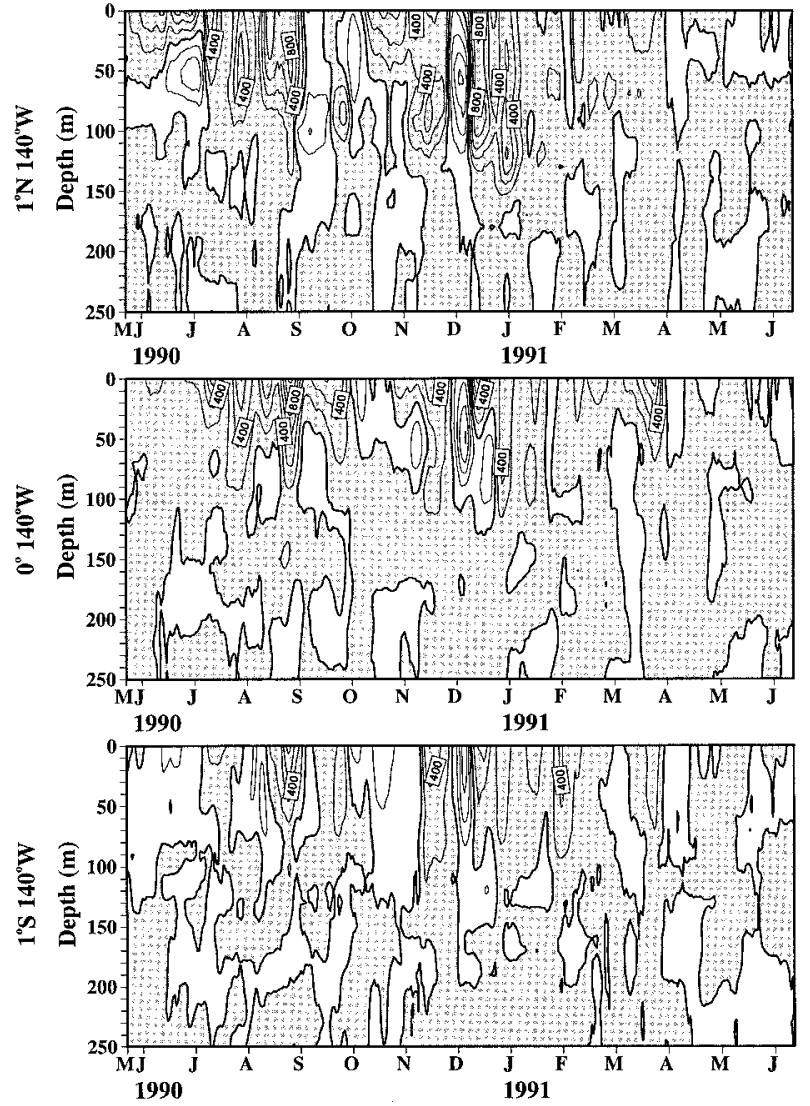

FIG. 3. Reynolds stress component $\left\langle u^{\prime} v^{\prime}\right\rangle$ as a function of time and depth at $1^{\circ} \mathrm{S}, 0^{\circ}$, and $1^{\circ} \mathrm{N}$ along $140^{\circ} \mathrm{W}$. Positive values are stippled and the contour interval is $200 \mathrm{~cm}^{2} \mathrm{~s}^{-2}$.

August to December 1990, thus defining the instability wave season.

The distributions with time, depth, and latitude $\left(1^{\circ} \mathrm{S}\right.$ to $1^{\circ} \mathrm{N}$ along $\left.140^{\circ} \mathrm{W}\right)$ for the horizontal Reynolds stress term $\left\langle u^{\prime} v^{\prime}\right\rangle$ (Fig. 3) show positive values during the instability wave season at all three latitudes with largest magnitudes at $1^{\circ} \mathrm{N}$ and smallest magnitudes at $1^{\circ} \mathrm{S}$. A large negative stress is also observed at all three latitudes in December 1990, coinciding with the termination of the instability waves. Vertically, the region of large positive values is confined to above the EUC core depth.

The Reynolds stress components $\left\langle u^{\prime} w^{\prime}\right\rangle$ and $\left\langle v^{\prime} w^{\prime}\right\rangle$ are calculated at $0^{\circ}, 140^{\circ} \mathrm{W}$, where the $w$ component is estimated from the observed $u$ and $v$ components using the continuity equation. A detailed discussion of $w$, including error estimates, comparisons with previous estimates, and implications regarding the upper-ocean heat balance are given in R. H. Weisberg and L. Qiao (manuscript in preparation), and the role of $w$ in the equatorial zonal momentum balance is discussed in Qiao and Weisberg (1997). For purposes herein it is noted that $w$ appears to be well resolved at the instability wave frequency. The results of $\left\langle u^{\prime} w^{\prime}\right\rangle$ and $\left\langle v^{\prime} w^{\prime}\right\rangle$ at $0^{\circ}, 140^{\circ} \mathrm{W}$ 

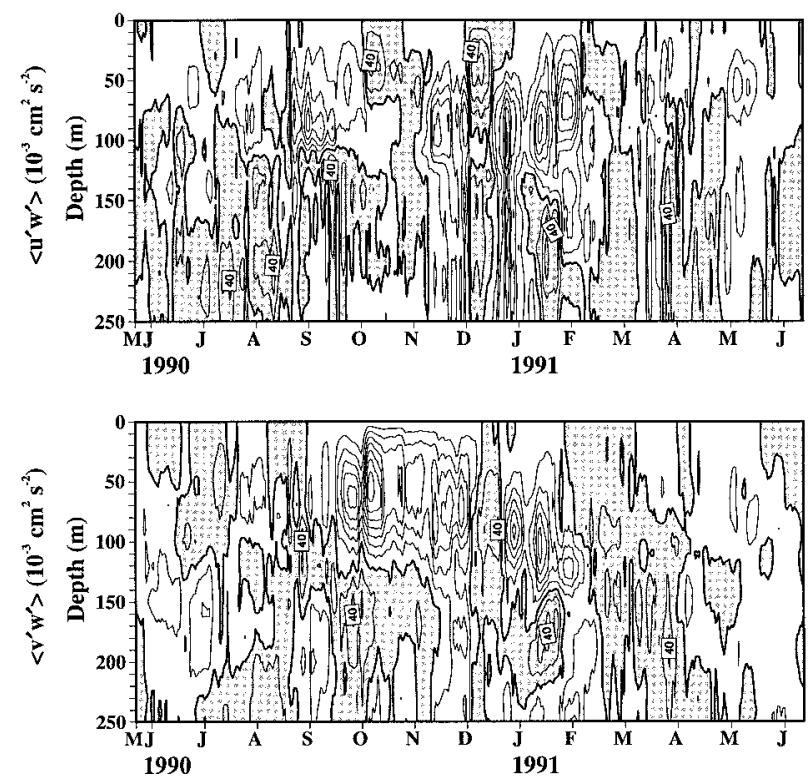

FIG. 4. Reynolds stress components $\left\langle u^{\prime} w^{\prime}\right\rangle$ and $\left\langle v^{\prime} w^{\prime}\right\rangle$ as functions of time and depth at $0^{\circ}, 140^{\circ} \mathrm{W}$. Positive values are stippled and the contour interval is $20 \mathrm{~cm}^{2} \mathrm{~s}^{-2}$.

are shown in Fig. 4. Both terms appear to be large from September 1990 to February 1991. Above the EUC core they tend to be negative and large and below the core they tend to be positive, but with relatively small magnitude.

All three off-diagonal components of Reynolds stress tensor $\left(\left\langle u^{\prime} v^{\prime}\right\rangle,\left\langle u^{\prime} w^{\prime}\right\rangle\right.$, and $\left.\left\langle v^{\prime} w^{\prime}\right\rangle\right)$ appear to be related to instability waves in that they all tend to be largest during the wave season. The $\left\langle u^{\prime} v^{\prime}\right\rangle$ is strongly surface confined with relative maxima either at the surface or in the upper layer above the EUC core. It is positive and large from July to September 1990 during the onset of the wave season. In contrast, the $\left\langle u^{\prime} w^{\prime}\right\rangle$ and $\left\langle v^{\prime} w^{\prime}\right\rangle$ terms extend deeper with relative amplitude maxima oftentimes occurring at depths between 50 and $80 \mathrm{~m}$ coinciding with the upper portion of the EUC (above the core).

To calculate the Reynolds density flux, the density distribution must first be estimated. The density distributions at $2^{\circ} \mathrm{S}, 0^{\circ}$, and $2^{\circ} \mathrm{N}$ along $140^{\circ} \mathrm{W}$ were estimated from the equation of state of seawater using the available temperature data at those locations and a constant salinity of $35 \mathrm{ppt}$ (salinity data is unavailable). The density distributions at $1^{\circ} \mathrm{S}, 140^{\circ} \mathrm{W}$ and $1^{\circ} \mathrm{N}, 140^{\circ} \mathrm{W}$ were then calculated by linear interpolation. Since the temperature was sampled daily while the current velocity was sampled hourly, the velocity data were reduced to daily averages for the Reynolds density flux calculation and the basic averaging length for calculating the mean, variance, and covariance in any of the terms involving density (and pressure gradient) was changed to 21 days instead of $500 \mathrm{~h}$. The Reynolds density fluxes by the $v$ component $\left(\left\langle v^{\prime} \rho^{\prime}\right\rangle\right)$ calculated at $1^{\circ} \mathrm{S}, 0^{\circ}$, and $1^{\circ} \mathrm{N}$ along
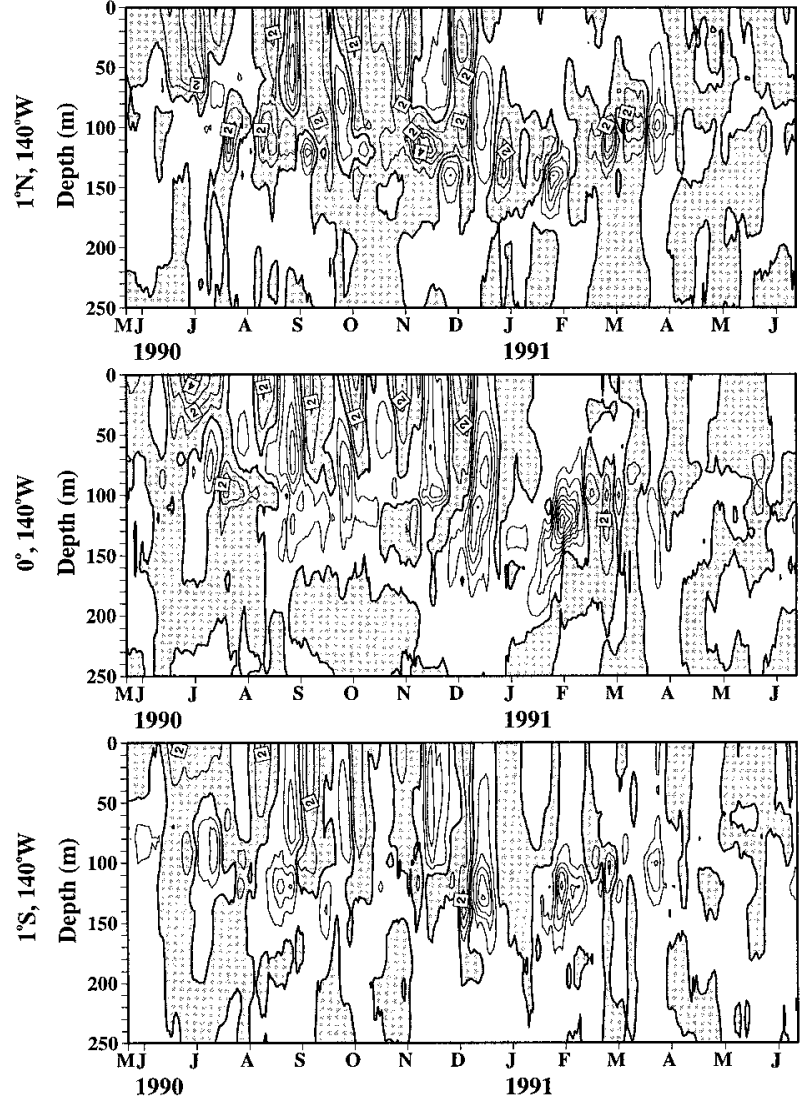

FIG. 5. Meridional constituent of the Reynolds density flux $\left\langle v^{\prime} \rho^{\prime}\right\rangle$ as a function of time and depth at $1^{\circ} \mathrm{S}, 0^{\circ}$, and $1^{\circ} \mathrm{N}$ along $140^{\circ} \mathrm{W}$. Positive values are stippled and the contour interval is $1 \times 10^{-3} \mathrm{~g}$ $\mathrm{cm}^{2} \mathrm{~s}^{-1}$.

$140^{\circ} \mathrm{W}$ are shown in Fig. 5. Large values of $\left\langle v^{\prime} \rho^{\prime}\right\rangle$ are observed before and during the instability wave season. After the wave season a large flux at the EUC core remains, but the flux above the core decreases. The magnitude of this flux is large from the surface to the EUC core with the largest magnitude generally located at the EUC core depth. The magnitudes of density fluxes increase to the north with a maximum for the array occurring at $1^{\circ} \mathrm{N}$.

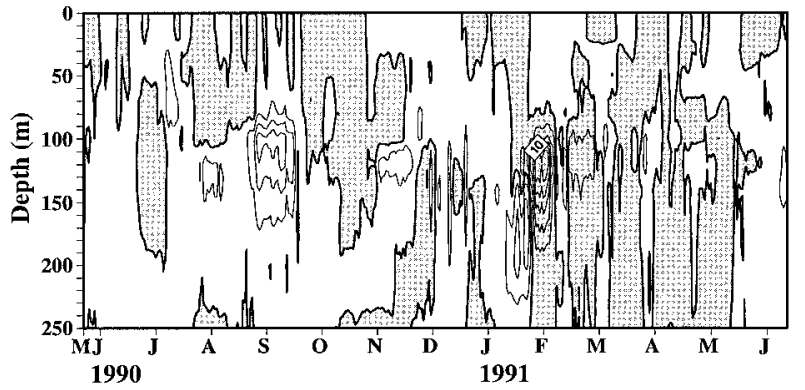

FIG. 6. Vertical constituent of the Reynolds density flux $\left\langle w^{\prime} \rho^{\prime}\right\rangle$ as a function of time and depth at $0^{\circ}, 140^{\circ} \mathrm{W}$. Positive values are stippled and the contour interval is $5 \times 10^{-7} \mathrm{~g} \mathrm{~cm}^{2} \mathrm{~s}^{-1}$. 

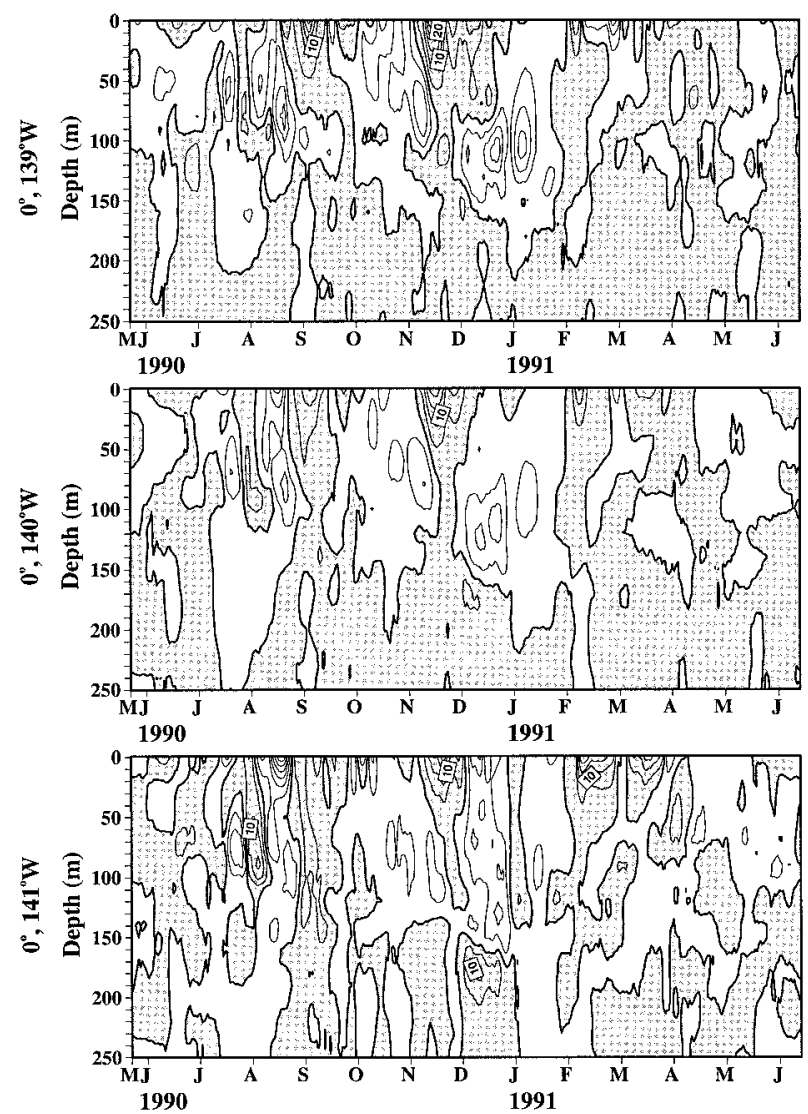

FIG. 7. Mean zonal divergence of perturbation horizontal kinetic energy at $141^{\circ}, 140^{\circ}$, and $139^{\circ} \mathrm{W}$ along equator. Positive values are stippled and the contour interval is $5 \times 10^{-4} \mathrm{~cm}^{2} \mathrm{~s}^{-3}$.

Reynolds density flux by the $w$ component $\left(\left\langle w^{\prime} \rho^{\prime}\right\rangle\right)$ at $0^{\circ}, 140^{\circ} \mathrm{W}$ is shown in Fig. 6. It is small except in September 1990 and again in January and February 1991. The large negative flux in September 1990 is confined between 70 and $170 \mathrm{~m}$ with a maximum amplitude at $120 \mathrm{~m}$. The subsequent time of large flux in January and February 1991 begins with negative values between 120 and $220 \mathrm{~m}$ and is followed by positive values between 80 and $180 \mathrm{~m}$.

\section{2) Mean divergence of PKE: Right-Hand Side OF $(1 \mathrm{~A})$}

The right-hand side of (1a) is the divergence of the PKE by the mean flow field. The mean zonal PKE divergence $-(U \mathrm{PKE})_{x}$ at $141^{\circ} \mathrm{W}, 140^{\circ} \mathrm{W}$, and $139^{\circ} \mathrm{W}$ along the equator is shown in Fig. 7. It has a magnitude of 2 $\times 10^{-3} \mathrm{~cm}^{2} \mathrm{~s}^{-3}$ and its zonal variation is small. Relatively large values are generally observed during the instability wave season within the upper $110 \mathrm{~m}$.

The mean meridional PKE divergence $-(V \mathrm{PKE})_{y}$ at $0.5^{\circ} \mathrm{S}, 0^{\circ}$, and $0.5^{\circ} \mathrm{N}$ along $140^{\circ} \mathrm{W}$ is shown in Fig. 8 . It has the same magnitude as - (UPKE) $)_{x}$. On the equator and at $0.5^{\circ} \mathrm{N}$ it shows a well-defined pattern with a sur-
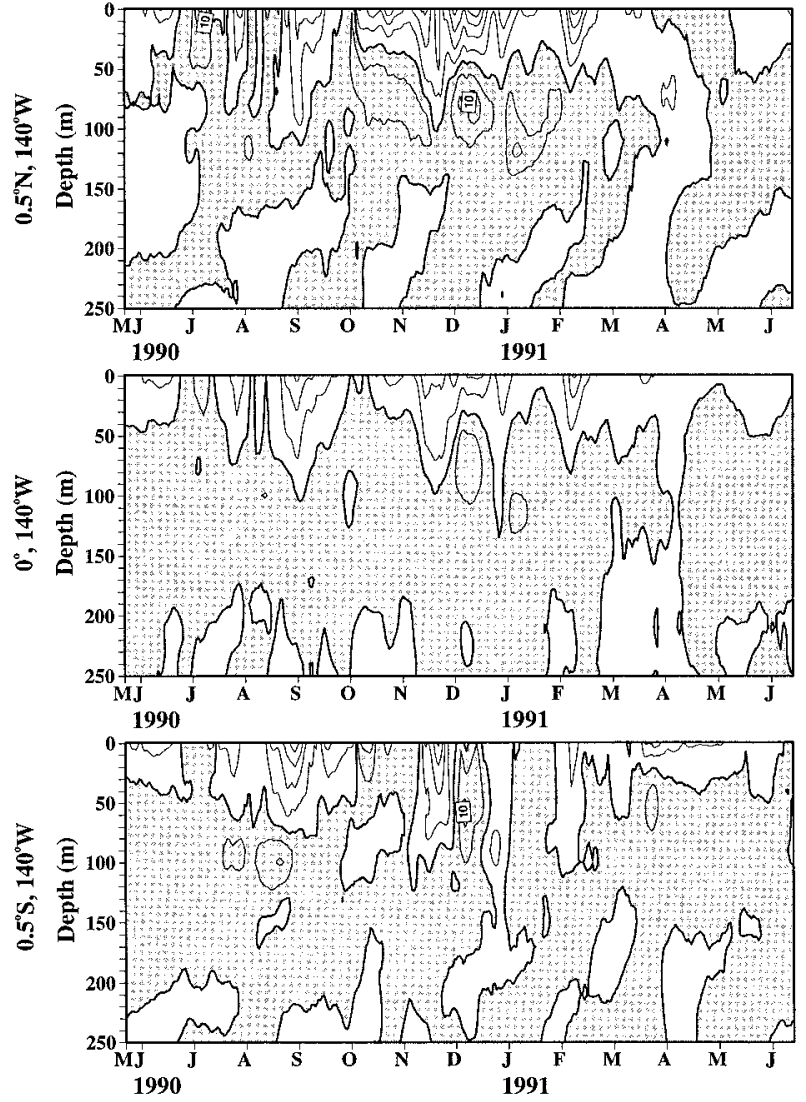

FIG. 8. Mean meridional divergence of perturbation horizontal kinetic energy at $0.5^{\circ} \mathrm{S}, 0^{\circ}$, and $0.5^{\circ} \mathrm{N}$ along $140^{\circ} \mathrm{W}$. Positive values are stippled and the contour interval is $5 \times 10^{-4} \mathrm{~cm}^{2} \mathrm{~s}^{-3}$.

face divergence and a subsurface convergence. The surface divergence and subsurface convergence are the consequence of the surface Ekman divergence and the subsurface geostrophic convergence of the mean flow field, respectively. Such tendency also occurs at $0.5^{\circ} \mathrm{S}$, but the pattern is not as well defined near the surface. At all locations this surface divergence and subsurface convergence pattern is largest during the instability wave season and tends to increase to the north.

The mean vertical divergence of PKE, $-(W \mathrm{PKE})_{z}$

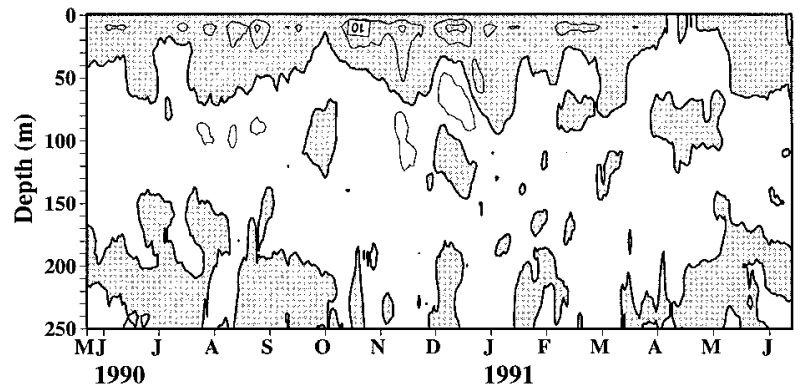

FIG. 9. Mean vertical divergence of perturbation horizontal kinetic energy at $0^{\circ}, 140^{\circ} \mathrm{W}$. Positive values are stippled and the contour interval is $5 \times 10^{-4} \mathrm{~cm}^{2} \mathrm{~s}^{-3}$. 


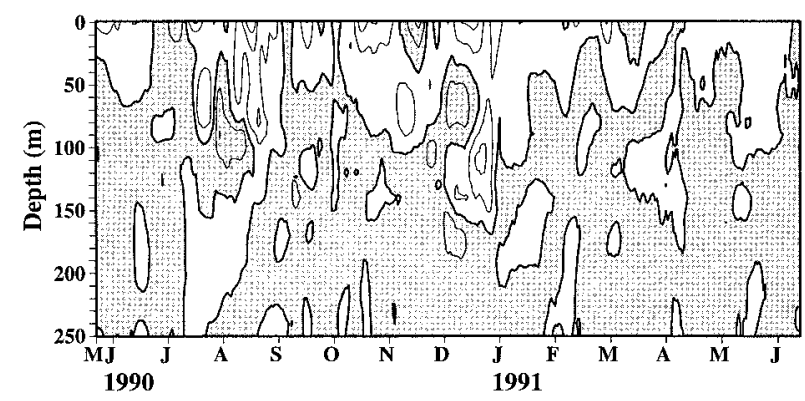

FIG. 10. Mean divergence of perturbation horizontal kinetic energy at $0^{\circ}, 140^{\circ} \mathrm{W}$. Positive values are stippled and the contour interval is $5 \times 10^{-4} \mathrm{~cm}^{2} \mathrm{~s}^{-3}$.

evaluated at $0^{\circ}, 140^{\circ} \mathrm{W}$ is shown in Fig. 9. It also shows a well-defined pattern, but with a convergence near the surface and a divergence below. It, therefore, tends to oppose the mean meridional PKE divergence at all depths, but with a relatively small magnitude $(1.5 \times$ $10^{-3} \mathrm{~cm}^{2} \mathrm{~s}^{-3}$ ) compared to the other two mean PKE divergence constituents.

Summing the three mean PKE divergence constituents gives the total mean PKE divergence [the righthand side of (1a)], as shown in Fig. 10 for $0^{\circ}, 140^{\circ} \mathrm{W}$. Its magnitude (of order $10^{-3} \mathrm{~cm}^{2} \mathrm{~s}^{-3}$ ) is similar to that of $-(W \mathrm{PKE})_{z}$, but relatively small compared to its other two constituents.

\section{3) ENERGY CONVERSION BETWEEN THE WAVES AND MEAN FLOW: (1B)}

The mean flow and the waves interact through the Reynolds stress tensor. A positive term in line (1b) implies conversion of kinetic energy from the mean flow to the instability waves and, conversely, a negative term implies a kinetic energy conversion from the waves to mean flow. The $-\left\langle u^{\prime} u^{\prime}\right\rangle U_{x}$ and $-\left\langle u^{\prime} v^{\prime}\right\rangle V_{x}$ terms calculated on the equator at $141^{\circ} \mathrm{W}, 140^{\circ} \mathrm{W}$, and $139^{\circ} \mathrm{W}$ are found to have relatively small magnitudes (generally $<0.5 \times 10^{-3} \mathrm{~cm}^{2} \mathrm{~s}^{-3}$.

The term $-\left\langle u^{\prime} v^{\prime}\right\rangle U_{y}$, is calculated at $0.5^{\circ} \mathrm{S}, 0^{\circ}$, and $0.5^{\circ} \mathrm{N}$ along $140^{\circ} \mathrm{W}$ and the results for each of the locations are shown in Fig. 11. On the equator and at $0.5^{\circ} \mathrm{S}$, this term is generally small except that relatively large values are observed at $0.5^{\circ} \mathrm{S}$ in November and December 1990. Of the three locations the largest values for this term are found at $0.5^{\circ} \mathrm{N}$. Positive values as large as $2 \times 10^{-3} \mathrm{~cm}^{2} \mathrm{~s}^{-3}$ are observed in July and August 1990 above the EUC core, implying that the instability waves are extracting energy from the mean flow field through the meridional gradient of the mean zonal velocity component. The average value of $10^{-3} \mathrm{~cm}^{2} \mathrm{~s}^{-3}$ is large enough to support the initial wave growth (with an $e$-folding timescale of 20 days and an energy level of $1300 \mathrm{~cm}^{2} \mathrm{~s}^{2}$ ). This energy source thus accounts for the generation of the instability waves during TIWE. Large fluctuations in this source are observed in Sep-
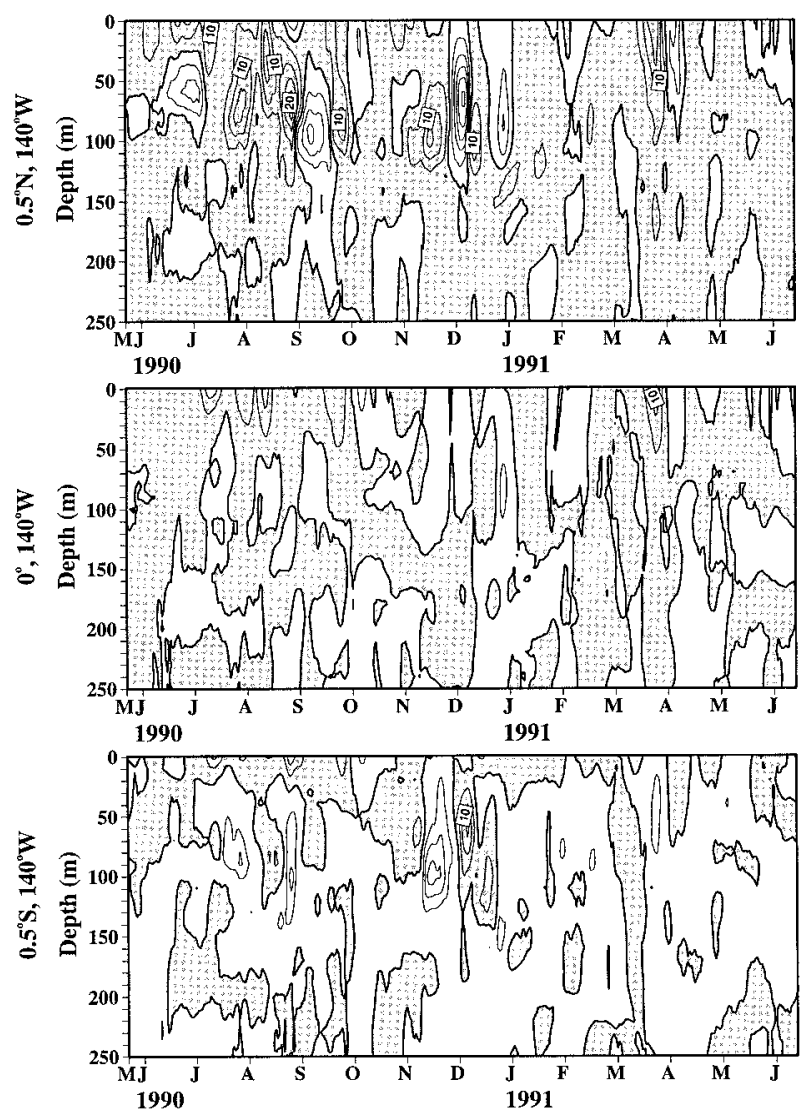

FIG. 11. Deformation work constituent $-\left\langle u^{\prime} v^{\prime}\right\rangle U_{y}$ as a function of time and depth at $0.5^{\circ} \mathrm{S}, 0^{\circ}$, and $0.5^{\circ} \mathrm{N}$ along $140^{\circ} \mathrm{W}$. Positive values are stippled and the contour interval is $5 \times 10^{-4} \mathrm{~cm}^{2} \mathrm{~s}^{-3}$.

tember, November, and December 1990. The large positive values in November followed by the large negative values in December 1990 are noteworthy because these conversions occur just before the termination of the instability wave season and tend to be antisymmetric about the equator with large negative values followed by large positive values occurring at $0.5^{\circ} \mathrm{S}$.

The $-\left\langle v^{\prime} v^{\prime}\right\rangle V_{y}$ results at $0.5^{\circ} \mathrm{S}, 0^{\circ}$, and $0.5^{\circ} \mathrm{N}$ along $140^{\circ} \mathrm{W}$ are shown in Fig. 12. At all three locations negative values are generally observed near the surface above a region of positive values. Because $\left\langle v^{\prime} v^{\prime}\right\rangle$ is positive definite, the sign of this term depends on the sign of $V_{y}$. Therefore, the negative surface and positive subsurface values result from the Ekman divergence and geostrophic convergence of the mean flow field, respectively. During the instability wave season the nearsurface negative values are large with magnitude of about $2 \times 10^{-3} \mathrm{~cm}^{2} \mathrm{~s}^{-3}$, and the magnitudes increase slightly to the south. Only at $0.5^{\circ} \mathrm{N}$ are relatively large positive values observed in September and October 1990 between 30 and $110 \mathrm{~m}$. Thus, on and to the south of the equator this term tends to weaken the instability waves, but to the north of the equator it may act as either a source or a sink of wave energy. 

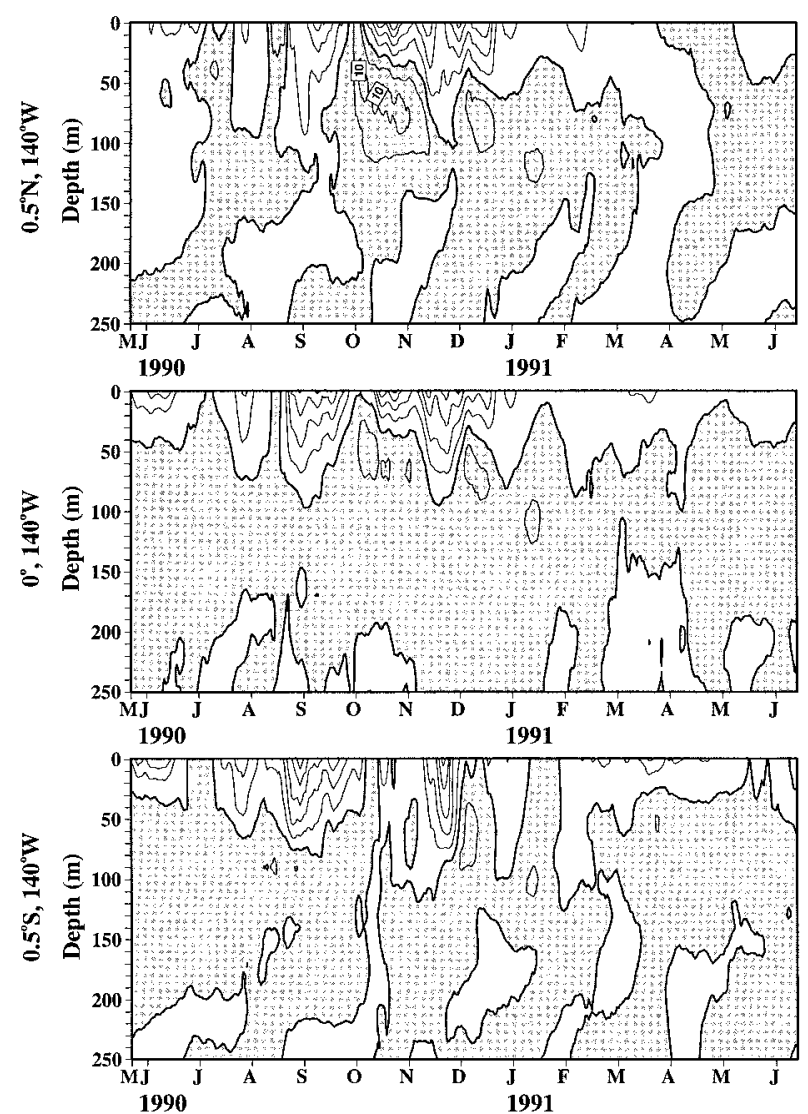

FIG. 12. Deformation work constituent $-\left\langle v^{\prime} v^{\prime}\right\rangle V_{y}$ as a function of time and depth at $0.5^{\circ} \mathrm{S}, 0^{\circ}$, and $0.5^{\circ} \mathrm{N}$ along $140^{\circ} \mathrm{W}$. Positive values are stippled and the contour interval is $5 \times 10^{-4} \mathrm{~cm}^{2} \mathrm{~s}^{-3}$.

Because the magnitudes of both $-\left\langle u^{\prime} v^{\prime}\right\rangle U_{y}$ and $-\left\langle v^{\prime} v^{\prime}\right\rangle V_{y}$ are equally large and at times of different sign, the sum of these two terms is given in Fig. 13 for the three locations along $140^{\circ} \mathrm{W}$. On the equator and at $0.5^{\circ} \mathrm{S}$ values larger than $1 \times 10^{-3} \mathrm{~cm}^{2} \mathrm{~s}^{-3}$ generally have a negative sign, occur only during the instability wave season, and are maximum at the surface. At these two locations, therefore, the combination of $-\left\langle u^{\prime} v^{\prime}\right\rangle U_{v}$ and $-\left\langle v^{\prime} v^{\prime}\right\rangle V_{y}$ acts as an energy sink for the instability waves with most of the conversion from the waves to the mean flow occurring near the surface. At $0.5^{\circ} \mathrm{N}$, in contrast, large positive values are observed in July and August extending from the surface to above the EUC core, representing a large kinetic energy conversion from the mean flow to the waves, as required for the initial instability wave growth. The negative values occurring in September 1990 coincide with the a period of decreasing wave energy (see Figure 1b). The modulation of this pattern from late July to December is in good agreement with the modulation of the wave amplitude throughout the 1990 tropical instability wave season.

The results of $-\left\langle u^{\prime} w^{\prime}\right\rangle U_{z}$ and $-\left\langle v^{\prime} w^{\prime}\right\rangle V_{z}$ at $0^{\circ}, 140^{\circ} \mathrm{W}$ are shown in Fig. 14. The term $-\left\langle u^{\prime} w^{\prime}\right\rangle U_{z}$, tends to
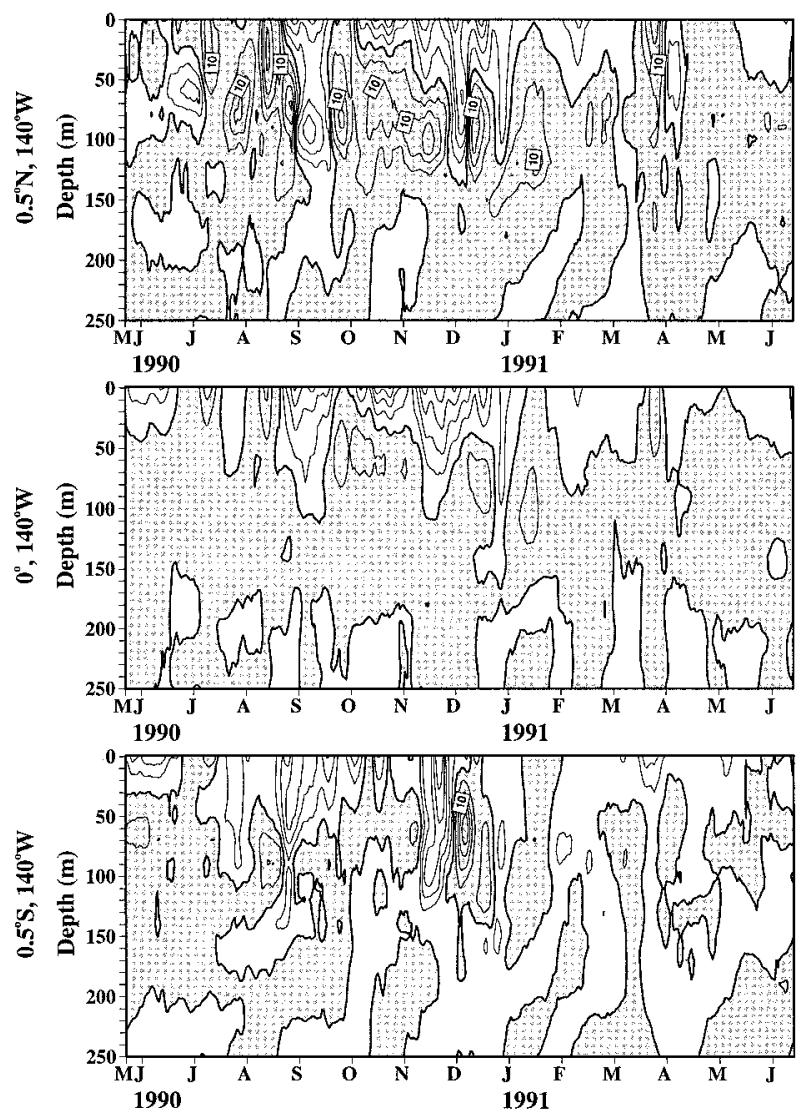

FIG. 13. The sum of the two leading deformation work constituents $-\left(\left\langle u^{\prime} v^{\prime}\right\rangle U_{y}+\left\langle v^{\prime} v^{\prime}\right\rangle V_{y}\right)$ as a function of time and depth at $0.5^{\circ} \mathrm{S}, 0^{\circ}$, and $0.5^{\circ} \mathrm{N}$ along $140^{\circ} \mathrm{W}$. Positive values are stippled and the contour interval is $5 \times 10^{-4} \mathrm{~cm}^{2} \mathrm{~s}^{-3}$
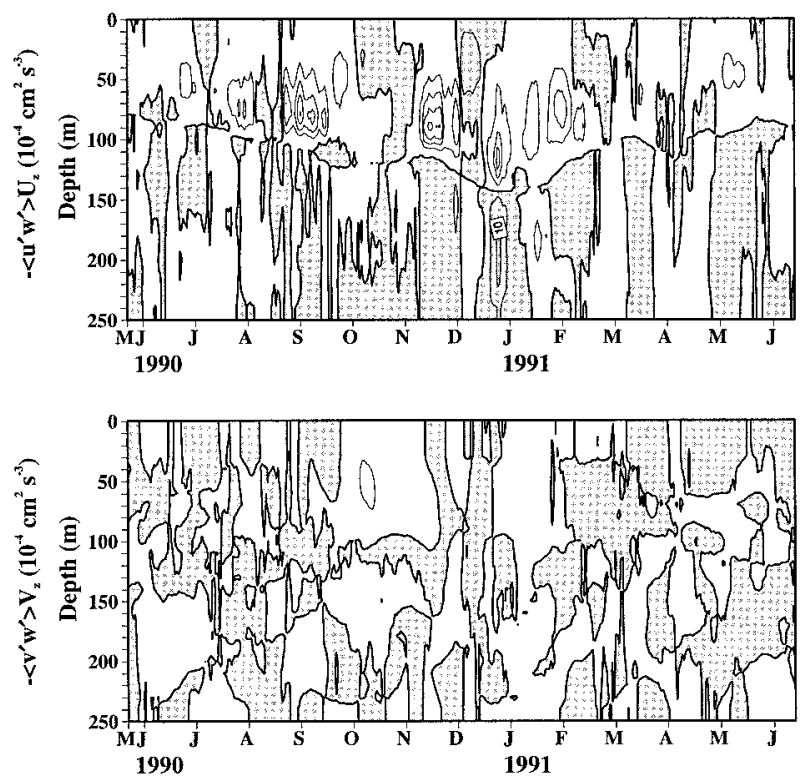

FIG. 14. Deformation work constituents $-\left\langle w^{\prime} u^{\prime}\right\rangle U_{z}$ and $-\left\langle v^{\prime} w^{\prime}\right\rangle V_{z}$ as functions of time and depth at $0^{\circ}, 140^{\circ} \mathrm{W}$. Positive values are stippled and the contour interval is $5 \times 10^{-4} \mathrm{~cm}^{2} \mathrm{~s}^{-3}$. 

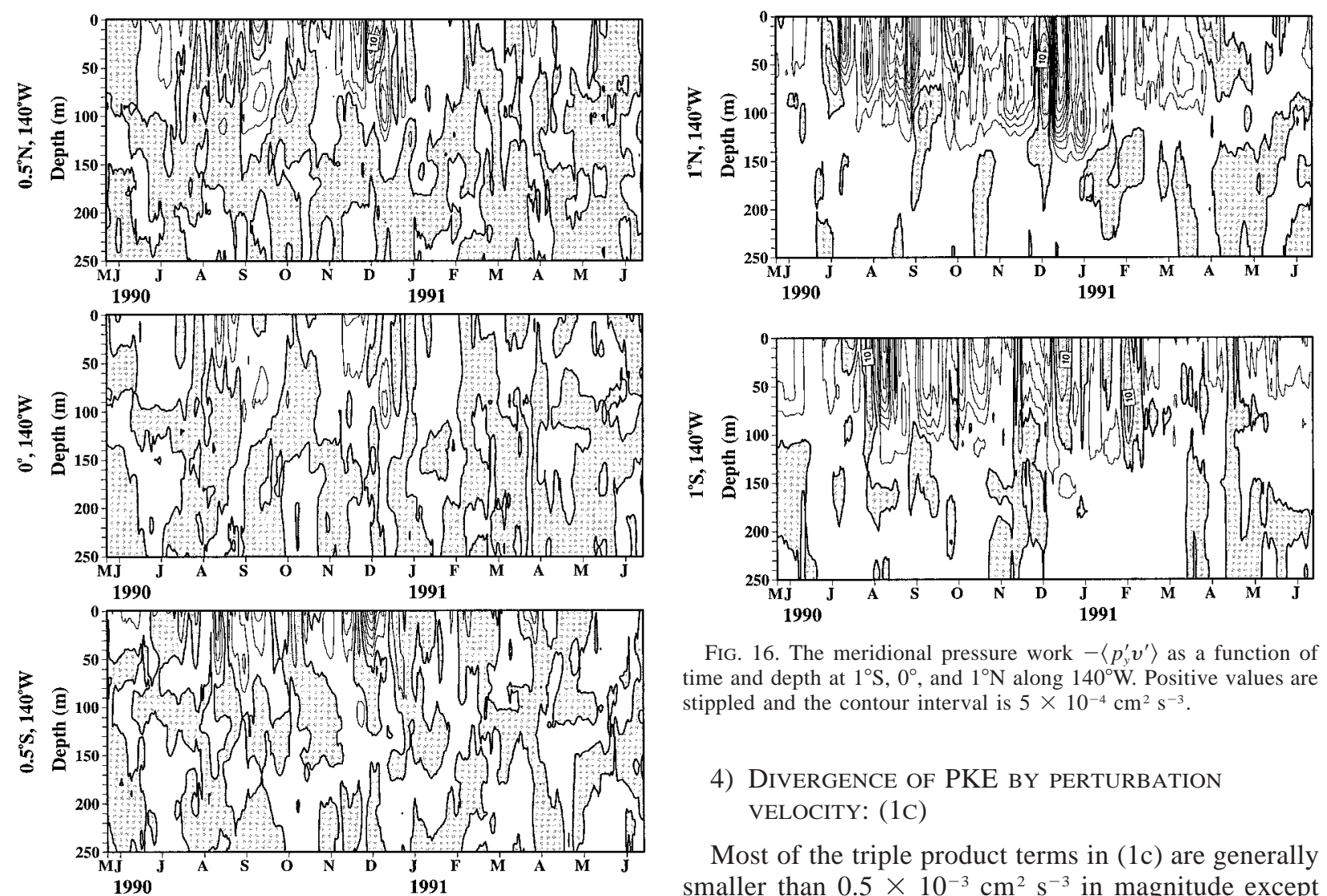

FIG. 16. The meridional pressure work $-\left\langle p_{v}^{\prime} v^{\prime}\right\rangle$ as a function of time and depth at $1^{\circ} \mathrm{S}, 0^{\circ}$, and $1^{\circ} \mathrm{N}$ along $140^{\circ} \mathrm{W}$. Positive values are stippled and the contour interval is $5 \times 10^{-4} \mathrm{~cm}^{2} \mathrm{~s}^{-3}$.

\section{4) Divergence of PKE by perturbation VELOCITY: (1C)}

Most of the triple product terms in (1c) are generally smaller than $0.5 \times 10^{-3} \mathrm{~cm}^{2} \mathrm{~s}^{-3}$ in magnitude except $-\left\langle\left(u^{\prime 2}+v^{\prime 2}\right) v^{\prime}\right\rangle_{y} / 2$, whose magnitude may be up to $2.5 \times 10^{-3} \mathrm{~cm}^{2} \mathrm{~s}^{-3}$ off the equator. The results for $-\left\langle\left(u^{\prime 2}+v^{\prime 2}\right) v^{\prime}\right\rangle_{y} / 2$ at $0.5^{\circ} \mathrm{S}, 0^{\circ}$, and $0.5^{\circ} \mathrm{N}$ along $140^{\circ} \mathrm{W}$ are shown in Fig. 15. Values tend to be large during the instability wave season over the upper $110 \mathrm{~m}$. They are also larger off the equator than on the equator. Since most of the large values are negative, this term generally tends to weaken the instability waves but, overall, the triple product terms are relatively weak compared with the deformation work terms.

\section{5) Pressure work: (1D)}

The meridional pressure gradient at $1^{\circ} \mathrm{S}$ and $1^{\circ} \mathrm{N}$ along $140^{\circ} \mathrm{W}$ is estimated using the density data (calculated from the temperature data) along $140^{\circ} \mathrm{W}$ between $2^{\circ} \mathrm{S}$ and $0^{\circ}$ and between $0^{\circ}$ and $2^{\circ} \mathrm{N}$ by referencing to 250 $\mathrm{m}$. The results for $-\left\langle p_{y}^{\prime} v^{\prime}\right\rangle$ at $1^{\circ} \mathrm{S}, 140^{\circ} \mathrm{W}$ and $1^{\circ} \mathrm{N}$, $140^{\circ} \mathrm{W}$ are shown in Fig. 16. Large values (with magnitude up to $4.5 \times 10^{-3} \mathrm{~cm}^{2} \mathrm{~s}^{-3}$ ) are observed at both locations (although generally larger at $1^{\circ} \mathrm{N}$ ) during the instability wave season and they tend to be confined to the upper $110 \mathrm{~m}$. The meridional pressure work is generally found to be negative except for short positive events lasting less than a month. Therefore, the meridional pressure work tends to weaken the instability waves by radiating perturbation energy meridionally out of the region being examined. The large positive and negative (antisymmetric about equator with negative 


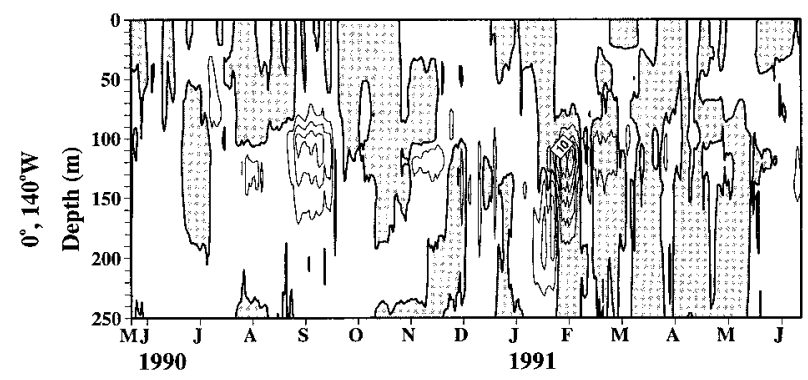

FIG. 17. The energy conversion between the wave kinetic energy and wave potential energy through buoyancy work $g\left\langle\rho^{\prime} w^{\prime}\right\rangle$ at $0^{\circ}$, $140^{\circ} \mathrm{W}$. Positive values are stippled and the contour interval is $5 \times$ $10^{-4} \mathrm{~cm}^{2} \mathrm{~s}^{-3}$.

and positive occurring at $1^{\circ} \mathrm{S}$ ) pressure work in November and December 1990 is noteworthy because it coincides with the termination of the instability wave season. The alternation of positive and negative pressure work appears to be related to the upwelling and downwelling phases of a Kelvin wave pulse that transited the array at that time. The antisymmetry about the equator for the pressure work divergence is consistent with the antisymmetric structure of the meridional pressure gradient field associated with a Kelvin wave. This differs from other terms during the instability wave season since the $v$ component and the meridional pressure gradient for the instability waves are both symmetric about the equator. The net effect of Kelvin waves through the $-\left\langle p_{y}^{\prime} v^{\prime}\right\rangle$ term, however, is not large since when integrated over the period of Kelvin wave the positive and negative value of $-\left\langle p_{y}^{\prime} v^{\prime}\right\rangle$ tend to cancel.

The $-\left\langle p_{z}^{\prime} w^{\prime}\right\rangle$ term $=-g\left\langle\rho^{\prime} w^{\prime}\right\rangle$ as pointed out earlier. It has the same values but opposite sign as $g\left\langle\rho^{\prime} w^{\prime}\right\rangle$, which is shown in Fig. 17 for $0^{\circ}, 140^{\circ} \mathrm{W}$. It is negligible most of time except in September 1990 and again in January and February 1991 between 80 and $220 \mathrm{~m}$. The positive values observed in September 1990 imply that PKE is convergent in the region between 80 and 180 $\mathrm{m}$. Overall, it is not as important as $-\left\langle p_{y}^{\prime} \boldsymbol{v}^{\prime}\right\rangle$ and relatively large values only exist for short duration.

With the available data $-\left\langle p_{x}^{\prime} u^{\prime}\right\rangle$ cannot be estimated. Although the temperature data at $170^{\circ}$ and $125^{\circ} \mathrm{W}$ on the equator are available, the distance between those locations is too large compared to the zonal wavelength of the instability waves. From equatorial Atlantic Ocean observations Weisberg and Weingartner (1988) found the zonal and meridional pressure work divergence terms to be equally large and opposite in sign. Since the temporal variation of the zonal pressure gradient in the Pacific is large (e.g., Wilson and Leetmaa 1988) there is no reason to expect that the zonal pressure work will be small, so it is likely that the $-\left\langle p_{y}^{\prime} v^{\prime}\right\rangle$ is offset by $-\left\langle p_{x}^{\prime} u^{\prime}\right\rangle$ as found in the Atlantic. Unfortunately, without a suitable estimate of $-\left\langle p_{x}^{\prime} u^{\prime}\right\rangle$, it is not possible to further evaluate the role of the pressure work divergence (1d) in radiating instability wave energy away from the equator.
6) ENERGy CONVERSION BETWEen PKE AND PPE: (1E)

The term $g\left\langle\rho^{\prime} w^{\prime}\right\rangle$ at $0^{\circ}, 140^{\circ} \mathrm{W}$ is shown in Fig. 17 . During the wave season, relatively large negative values are observed in September 1990 between 80 and 180 $\mathrm{m}$, suggesting that $\mathrm{PKE}$ is being converted to PPE through buoyancy work. Because the $g\left\langle\rho^{\prime} w^{\prime}\right\rangle$ term is the only term that links the PKE and the PPE, its negative values suggest that near the equator there is no net contribution to the large horizontal velocity oscillations (the PKE) by baroclinic conversion. Locally, the work against the buoyancy force tends to reduce the current fluctuations. Thus, the PPE near the equator cannot account for the large near-equator PKE. Nevertheless, the PPE equation will be examined to further support of this conclusion and for comparisons with previous findings.

7) Summarizing the RIGHT-HAnd Side of EQ. (1)

The terms that are important for the kinetic energy balance of the instability waves are

$$
\begin{aligned}
& \left\langle u^{\prime} v^{\prime}\right\rangle U_{y}, \quad-\left\langle v^{\prime} v^{\prime}\right\rangle V_{y}, \quad-\left\langle u^{\prime} w^{\prime}\right\rangle U_{z}, \\
& -\frac{1}{2}\left\langle\left(u^{\prime 2}+v^{\prime 2}\right) v^{\prime}\right\rangle_{y}, \quad-\left\langle p_{y}^{\prime} v^{\prime}\right\rangle, \quad-\left\langle p_{x}^{\prime} u^{\prime}\right\rangle, \\
& -\left\langle p_{z}^{\prime} w^{\prime}\right\rangle, \quad g\left\langle\rho^{\prime} w^{\prime}\right\rangle .
\end{aligned}
$$

The first three terms represent the energy conversion between the instability waves and mean flow field; the fourth represents the flux divergence of the PKE by the perturbation themselves; the fifth to seventh represent the pressure work; and the last one gives the energy conversion between the kinetic and potential energy. The sum of the first two terms north of the equator above the EUC core depth is large and positive during the onset of the instability wave season, and it appears to account quantitatively for the initial instability wave growth observed during TIWE. Its temporal variation is also generally in agreement with the amplitude modulation of the $v$-component instability wave fluctuations (Fig. 1b). Thus, barotropic instability within the cyclonic shear region of the mean horizontal velocity field is an important energy source for the instability waves. Near the surface $-\left\langle\boldsymbol{v}^{\prime} \boldsymbol{v}^{\prime}\right\rangle V_{y}$ is an energy sink for the instability waves. However, owing to the geostrophic convergence of fluid just below the surface layer, this term augments the wave growth just north of the equator. The third interaction term $-\left\langle u^{\prime} w^{\prime}\right\rangle U_{z}$ tends to weaken the instability waves.

The pressure work divergence represents the effect of wave energy propagation. The $-\left\langle p_{y}^{\prime} v^{\prime}\right\rangle$ term tends to weaken the instability wave by radiating the wave energy meridionally out of the region examined, while a compensating energy propagation into the region through $-\left\langle p_{x}^{\prime} u^{\prime}\right\rangle$ can only be inferred from previous observations. On the equator $-\left\langle p_{z}^{\prime} w^{\prime}\right\rangle$ shows a conver- 

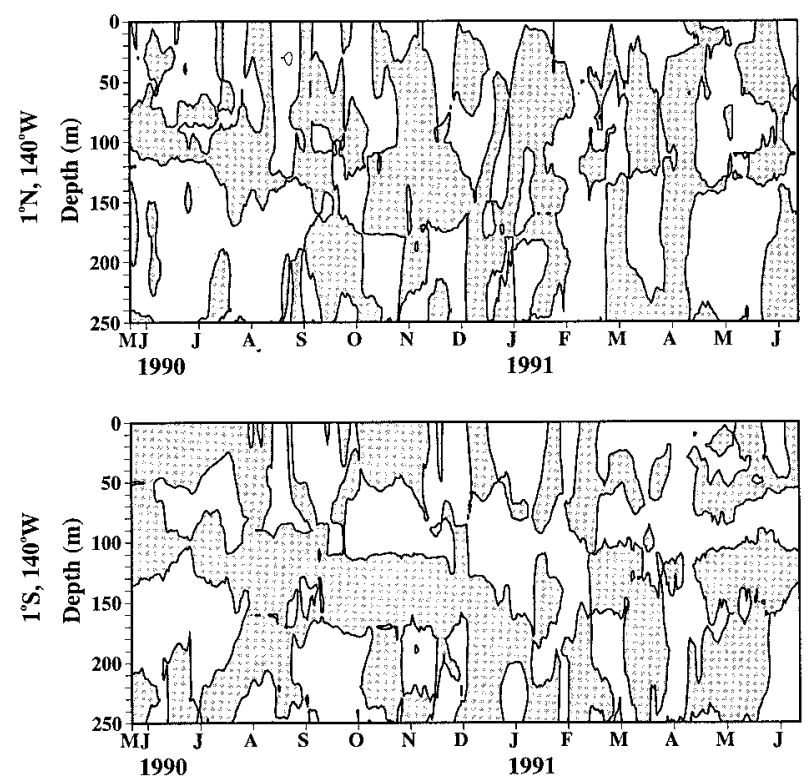

FIG. 18. Mean meridional advection of perturbation potential energy at $1^{\circ} \mathrm{S}$ and $1^{\circ} \mathrm{N}$ along $140^{\circ} \mathrm{W}$. Positive values are stippled and the contour interval is $5 \times 10^{-4} \mathrm{~cm}^{2} \mathrm{~s}^{-3}$.

gence of wave kinetic energy within the region between 80 and $180 \mathrm{~m}$ where it is converted to potential energy by $g\left\langle\rho^{\prime} w^{\prime}\right\rangle$.

\section{b. Perturbation potential energy}

1) Advection of PPE By THE MEAN VELOCITY: RIGHT-HAND SIDE OF (2A)

Of the three advection terms on the right-hand side of (2a) only the advection of PPE by the mean meridional $\left[-V(\mathrm{PPE})_{y}\right]$ and by the mean vertical $\left[-W(\mathrm{PPE})_{z}\right]$ velocity components can be estimated. The values of both terms are generally smaller than $10^{-3} \mathrm{~cm}^{2} \mathrm{~s}^{-3}$ (Figs. 18 and 19). Qiao and Weisberg (1997) described the circulation associated with the Equatorial Undercurrent as fully three-dimensional with all three constituents of the zonal momentum divergence being of the same magnitude. The mean divergence of the PKE results also suggests that the magnitude of mean divergence itself is not larger than any of its constituents. Thus, it is reasonable to assume that the total mean advection of the PPE generally has magnitude smaller than the individual terms $-V(\mathrm{PPE})_{y}$ and $-W(\mathrm{PPE})_{z}\left(10^{-3} \mathrm{~cm}^{2} \mathrm{~s}^{-3}\right)$ even though the $-U(\mathrm{PPE})_{x}$ cannot be estimated. If this is true then the mean advection of PPE is not of primary importance in the instability wave energy balance near the equator.

\section{2) ENERGY CONVERSION BETWEEN THE WAVES AND THE MEAN DENSITY FIELD: (2B)}

The energy conversion between the wave potential energy and the mean density field through the mean

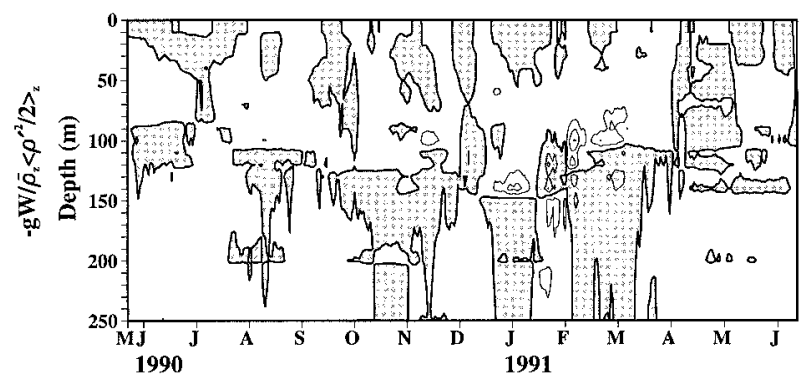

FIG. 19. Mean vertical advection of perturbation potential energy at $0^{\circ}, 140^{\circ} \mathrm{W}$. Positive values are stippled and the contour interval is $5 \times 10^{-4} \mathrm{~cm}^{2} \mathrm{~s}^{-3}$.

meridional density gradient $\left(-g \bar{\rho}_{y}\left\langle\rho^{\prime} \boldsymbol{v}^{\prime}\right\rangle / \bar{\rho}_{z}\right)$ is calculated for locations $1^{\circ} \mathrm{S}, 140^{\circ} \mathrm{W}$ and $1^{\circ} \mathrm{N}, 140^{\circ} \mathrm{W}$ (Fig. 20. The energy conversion by this mechanism (baroclinic instability) is small (usually smaller than $10^{-3} \mathrm{~cm}^{2}$ $\mathrm{s}^{-3}$ ) at both locations although observed values are slightly larger during the instability wave season. The potential energy conversion through the mean zonal density gradient $\left(-g \bar{\rho}_{x}\left\langle\rho^{\prime} u^{\prime}\right\rangle / \bar{\rho}_{z}\right)$ cannot be estimated, but Weisberg and Weingartner (1988) found for the Atlantic that $-g \bar{\rho}_{x}\left\langle\rho^{\prime} u^{\prime}\right\rangle / \bar{\rho}_{z}$ had the same magnitude as $\left.-g \bar{\rho}_{y}\left\langle\rho^{\prime} v^{\prime}\right\rangle\right) / \bar{\rho}_{z}$ and tended to oppose it. Since the value of $\bar{\rho}_{x}$ near the equator is generally smaller than that of $\bar{\rho}_{y}$ at $1^{\circ} \mathrm{N}$ ( $\overline{\boldsymbol{\rho}}_{y}$ tends to be zero on the equator), and since $\left\langle\rho^{\prime} u^{\prime}\right\rangle$ is not expected to be substantially larger than $\left\langle\rho^{\prime} v^{\prime}\right\rangle$ it is reasonable to assume that $-g \bar{\rho}_{x}\left\langle\rho^{\prime} u^{\prime}\right\rangle / \bar{\rho}_{z}$ is not larger than the estimated $\left.-g \bar{\rho}_{y}\left\langle\rho^{\prime} v^{\prime}\right\rangle\right) / \bar{\rho}_{z}$.
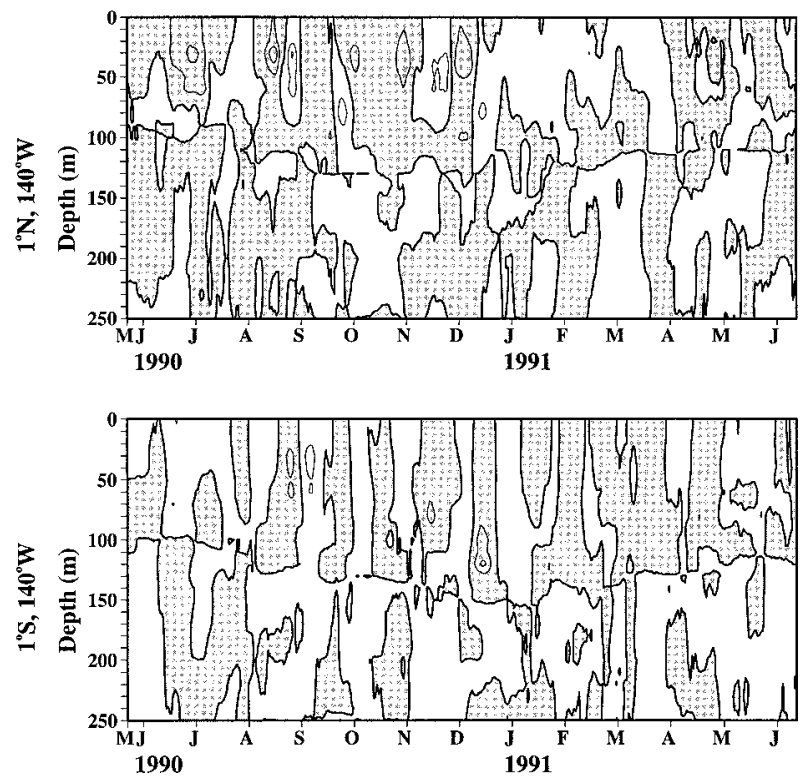

FIG. 20. The baroclinic energy conversion between the wave potential energy and the mean density field through meridional density gradient $\left.-g \bar{\rho}_{y}\left\langle\rho^{\prime} v^{\prime}\right\rangle\right) / \bar{\rho}_{z}$ at $1^{\circ} \mathrm{S}$ and $1^{\circ} \mathrm{N}$ along $140^{\circ} \mathrm{W}$. Positive values are stippled and the contour interval is $5 \times 10^{-4} \mathrm{~cm}^{2} \mathrm{~s}^{-3}$. 
3) AdVection of PPE by PERTURbation VELOCITY: (2C)

Two of the three terms in (2c) representing the advection of PPE by the perturbation velocity of the meridional $\left(-\left(\frac{1}{2}\right) g\left\langle\rho_{y}^{\prime 2} \boldsymbol{v}^{\prime}\right\rangle / \bar{\rho}_{z}\right)$ and the vertical $\left(-(1 / 2) g\left\langle\rho_{z}^{\prime 2} w^{\prime}\right\rangle / \bar{\rho}_{z}\right)$ components, respectively, that can be estimated are found to be small with values not exceeding $0.5 \times 10^{-3} \mathrm{~cm}^{2} \mathrm{~s}^{-3}$. This is consistent with previous findings that these triple product terms are not important for instability wave energy balance (e.g., Weisberg and Weingartner 1988; Luther and Johnson 1990).

\section{4) ENERgy CONVERSiOn BETWEen PKE AND PPE:} (2D)

The link between the PKE and the PPE equations, $g\left\langle\rho^{\prime} w^{\prime}\right\rangle$, shows that PPE is being generated at the expense of PKE. Thus, baroclinic processes in sum tend to decrease PKE at this location.

\section{5) Summarizing the RIGHT-HAND SIDE OF EQ.}

The only estimated term of importance on the righthand side of Eq. (2) is the potential energy conversion from the kinetic energy through the buoyancy force. Therefore, on the equator an increase in potential energy appears as a consequence, as opposed to a cause, of the instability waves.

\section{Discussion and conclusions}

Current velocity data from the TIWE array have been used to assess the energetics of the tropical instability waves that were observed in the central Pacific during 1990. The important terms in the perturbation energy equations are $-\left\langle u^{\prime} v^{\prime}\right\rangle U_{y},-\left\langle\boldsymbol{v}^{\prime} \boldsymbol{v}^{\prime}\right\rangle V_{y},-\left\langle u^{\prime} w^{\prime}\right\rangle U_{z}$, $-(1 / 2)\left\langle\left(u^{\prime 2}+v^{\prime 2}\right) v^{\prime}\right\rangle_{y},-\left\langle p_{y}^{\prime} v^{\prime}\right\rangle,-\left\langle p_{x}^{\prime} u^{\prime}\right\rangle,-\left\langle p_{z}^{\prime} w^{\prime}\right\rangle$, and $g\left\langle\rho^{\prime} w^{\prime}\right\rangle$ (or $-g\left\langle\rho^{\prime} w^{\prime}\right\rangle$ ). The term $-\left\langle u^{\prime} v^{\prime}\right\rangle U_{y}$ (Fig. 11) is large in the SEC and the upper portion of the EUC just north of the equator, and it appears to provide the energy source for the onset of the instability wave season. After this initial growth, the instability waves appear to be maintained by a combination of $-\left\langle u^{\prime} v^{\prime}\right\rangle U_{y}$ and $-\left\langle v^{\prime} v^{\prime}\right\rangle V_{y}$ (Fig. 13) just to the north of the equator. In contrast, the $-\left\langle v^{\prime} v^{\prime}\right\rangle V_{y}$ (Fig. 12) on and south of the equator, the $-\left\langle u^{\prime} w^{\prime}\right\rangle U_{z}$ (Fig. 14) on the equator and the $\left.-(1 / 2)\left\langle u^{\prime 2}+v^{\prime 2}\right) v^{\prime}\right\rangle_{y}$ (Fig. 15) at all locations provide sinks for the perturbation energy. The former two act to convert the wave energy to the mean flow and the latter acts to weaken the waves through the meridional divergence of the PKE by the perturbation velocity field. The $-\left\langle p_{y}^{\prime} v^{\prime}\right\rangle$ (Fig. 16) weakens the instability waves, but a local countereffect by $-\left\langle p_{x}^{\prime} u^{\prime}\right\rangle$ may be inferred from previous studies. Vertically, $-\left\langle p_{z}^{\prime} w^{\prime}\right\rangle$ (Fig. 17) propagates kinetic energy to the region between 80 and $180 \mathrm{~m}$, where the kinetic energy is converted to the potential energy by $g\left\langle\rho^{\prime} w^{\prime}\right\rangle$ (Fig. 17).
These results support the kinematical implications of Qiao and Weisberg (1995), from the tilt of the velocity hodographs into the cyclonic shear of the SEC, that barotropic instability is the most important source of wave energy locally. The energy conversion from the meridional shear of mean zonal flow $-\left\langle u^{\prime} v^{\prime}\right\rangle U_{y}$ is found to be large at $0.5^{\circ} \mathrm{N}, 140^{\circ} \mathrm{W}$ during the onset of the wave season. It decreases southward and at $0.5^{\circ} \mathrm{S}$ is much smaller and positive only above $30 \mathrm{~m}$, in good agreement with the decrease in the hodograph tilts to the south.

Similarly, Weisberg and Weingartner (1988) found that barotropic instability within the cyclonic shear region of the SEC is the energy source for the instability waves in the Atlantic Ocean. For the relatively short wave season in the Atlantic, they found that the energy production by $-\left\langle u^{\prime} v^{\prime}\right\rangle U_{y}$ is sufficient to generate and to maintain the waves. During TIWE, while $-\left\langle u^{\prime} v^{\prime}\right\rangle U_{y}$ is found to be large during the onset of the waves, it did not remain large over the entire wave season that lasted roughly four months. After the onset of the wave season, the instability waves appear to be maintained and modulated by the sum of $-\left\langle u^{\prime} v^{\prime}\right\rangle U_{y}$ and $-\left\langle v^{\prime} v^{\prime}\right\rangle V_{y}$.

It is apparent from previous studies and the TIWE data analysis that barotropic instability at and just north of the equator is the main energy source for the instability waves observed near the equator. The existence of both the SEC and the EUC is important for the waves to develop; however, the role of the EUC in the wave energy balance needs to be further clarified. Qiao and Weisberg (1995) hypothesized that the EUC helps the SEC go unstable by promoting the necessary meridional shear and curvature, while the EUC itself is stable owing to the planetary vorticity gradient and meridional flow convergence. The result of the energy balance shows that maximum energy conversion from the mean horizontal flow field to the waves generally occurs within the SEC and the upper portion of the EUC above the EUC core. Since $-\left\langle u^{\prime} w^{\prime}\right\rangle U_{z}$ is a sink (negative) for wave energy and it is generally largest in the upper portion of the EUC, it tends to oppose the conversion from the mean current to the waves, thereby reducing the contribution by the EUC. Thus, the entire depth range of the SEC is involved with the onset of the wave season, whereas only the upper part of the EUC makes a contribution and this contribution is reduced by stability arising from the vertical shear of the mean zonal velocity component.

In contrast to the conventional barotropic instability term $-\left\langle u^{\prime} v^{\prime}\right\rangle U_{y}$, the finding of $-\left\langle v^{\prime} v^{\prime}\right\rangle V_{y}$ as a significant factor for modulating the instability waves is a new result. Luther and Johnson (1990) suggested a similar vertical structure for this term, on average, but the relative magnitude compared to that of $-\left\langle u^{\prime} v^{\prime}\right\rangle U_{y}$ was found to be small. This term is related to both the meridional convergence of the mean flow field and the kinetic energy associated with the waves. As fluid converges on the equator, the energy associated with the 

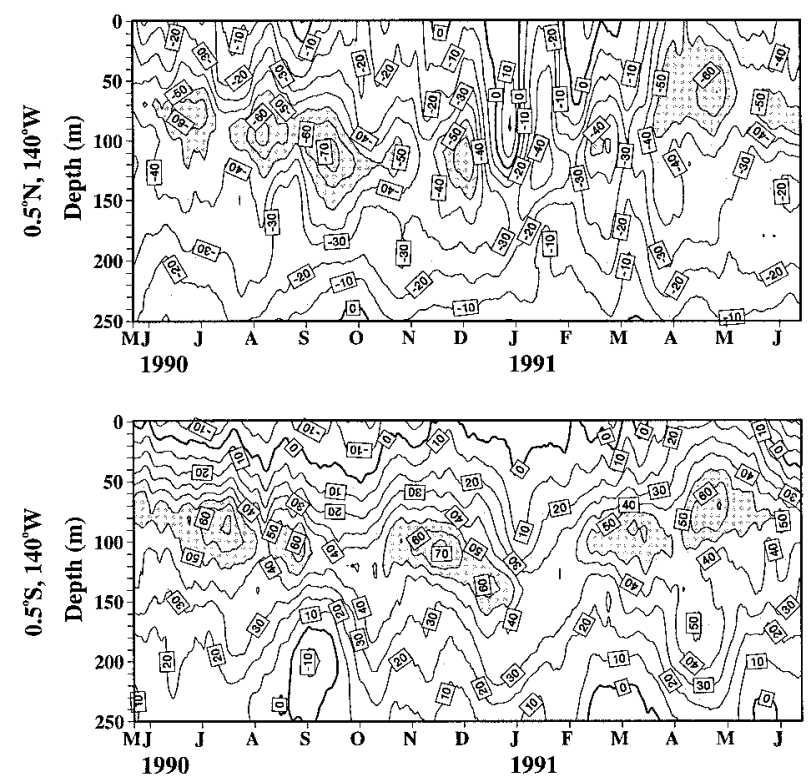

FIG. 21. The meridional shear of zonal velocity component as a function of time and depth at $0.5^{\circ} \mathrm{S}, 140^{\circ} \mathrm{W}$, and $0.5^{\circ} \mathrm{N}, 140^{\circ} \mathrm{W}$. Cyclonic shear (negative in the Northern Hemisphere and positive in the Southern Hemisphere) is stippled and the contour interval is $10^{-6}$ $\mathrm{s}^{-1}$.

waves also converges. It seems unlikely for this term to initially generate the instability waves because $\left\langle v^{\prime} v^{\prime}\right\rangle$ (Fig. 2) is small before the waves are fully developed and $V_{y}$ is symmetric about the equator, whereas the waves are not. Another requirement for this mechanism is a strong eastward directed zonal pressure gradient force, which results in a geostrophic convergence on the equator. This term may therefore be thought of as resulting from a positive feedback between the waves and the background field.

The termination of the instability waves during TIWE coincided with the passage of an eastward propagating Kelvin wave in December 1990. Kelvin waves may affect the instability waves by modifying the background velocity field, decreasing the meridional shear of the combined SEC and EUC and altering the energy conversions. While speculative, such an idea is supported by the temporal evolution of the meridional shear of the zonal velocity component at $0.5^{\circ} \mathrm{N}$ (shown in Fig. 21): the cyclonic shear is large in August and September 1990, relatively small during the remainder of wave season, and smallest after the Kelvin wave transits the array. After March 1991, while the shear increased, the surface current was no longer westward.

The meridional pressure work is found to radiate wave energy away; however, since the zonal constituent of the pressure work divergence $-\left\langle p_{x}^{\prime} u^{\prime}\right\rangle$ could not be estimated, the net effect of the pressure work divergence remains unclear. In the Atlantic, Weisberg and Weingartner (1988) found that the meridional pressure work was also negative. Their estimates of the zonal pressure work divergence suggested that it offset the meridional pressure work divergence, but not completely, leaving the deformation work as the primary energy source and meridional pressure work divergence as the primary energy sink. Luther and Johnson (1990) similarly found a negative meridional pressure work divergence south of $1^{\circ} \mathrm{N}$ but a large positive one between $1^{\circ} \mathrm{N}$ and $3^{\circ} \mathrm{N}$. The zonal pressure work is the only term that could not be estimated in the perturbation kinetic energy equation and is probably the only significant term of all the other unavailable terms in the wave energetics. The zonal separation of the TAO array is too large to resolve fluctuations on the scale of the instability waves, so this pressure work divergence remains an issue of outstanding importance.

The mean divergence of the PKE by the background flow field is relatively unimportant on the equator. However, this energetics result again demonstrates that the mean flow field about the equator is fully three-dimensional as concluded in the zonal momentum study by Qiao and Weisberg (1996). Each of the individual constituents has similar magnitude and they tend to cancel, leaving the total mean PKE divergence smaller than or similar to any of its constituents.

The role of the vertical velocity component in the instability wave energetics on the equator is included in the analysis. The large negative vertical shear in the background zonal velocity component above the EUC core results in an energy conversion from the waves to mean flow. The $w$ component also tends to convert wave kinetic energy to potential energy. These two effects both tend to stabilize the background current on the equator.

There are several terms in the perturbation energy equations that cannot be estimated. These terms are related to the zonal variation of either the density field or the pressure field. The contribution from the variation of the density field should be smaller than that from the pressure field because the pressure results from the vertical integration of the density. This idea is supported by the result of the meridional pressure work and of the terms related to the meridional density field. Further support may also be found in Weisberg and Weingartner (1988) and Luther and Johnson (1990). Therefore, the only significant term missing from this analysis is the zonal pressure work divergence.

McCreary and Yu (1992) and Yu et al. (1995) suggested that the SST front found to the north of the equator is an essential part of the tropical instability wave dynamics. They found that frontal instability, which is related to baroclinic instability associated with the horizontal temperature (density) gradient, is the main source for the wave energy in their numerical model simulation. In contrast, the results from the TIWE array show that the baroclinic instability due to the mean meridional temperature (density) gradient is small compared to the barotropic instability, although it does increase during the wave season. However, it should be noted that this analysis only covers the latitudes between 
$6 / 24 / 90-6 / 30 / 90$

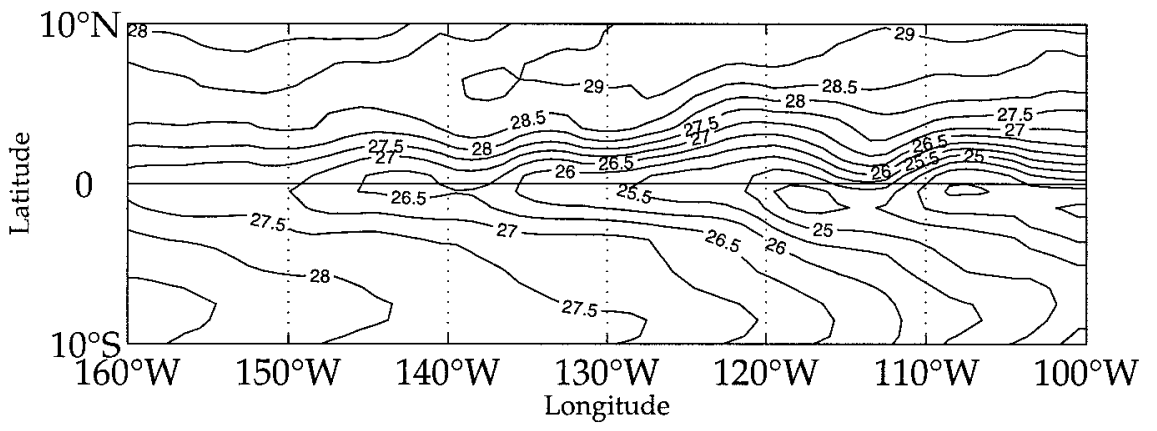

$9 / 23 / 90-9 / 29 / 90$

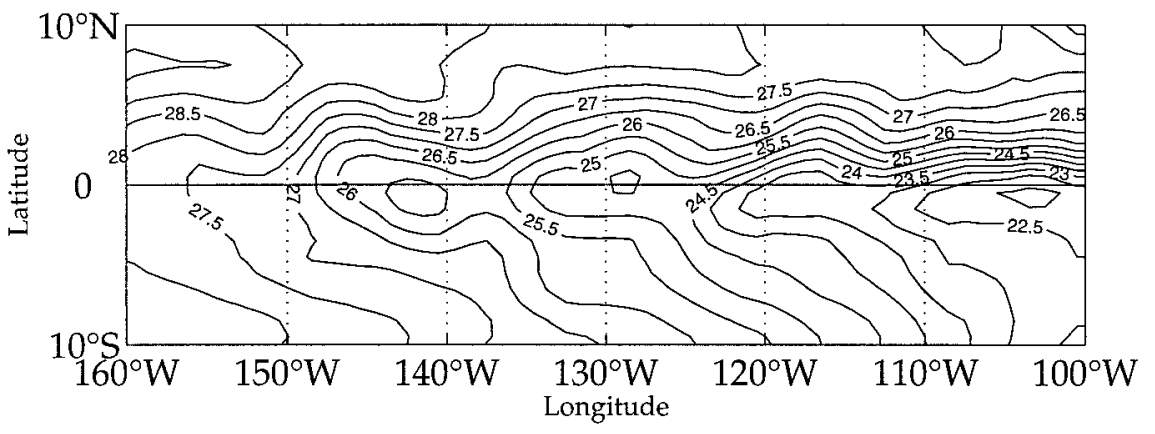

$1 / 13 / 91-1 / 19 / 91$

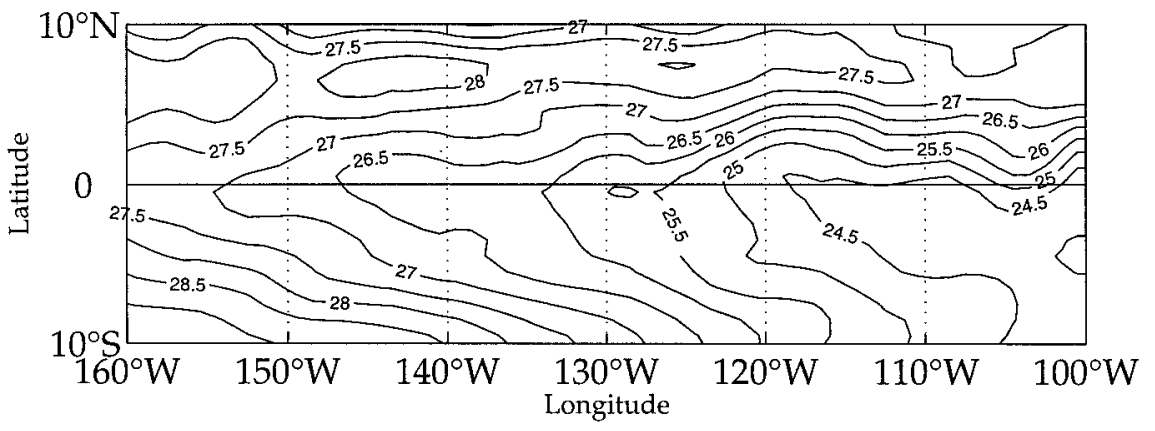

FIG. 22. The weekly mean sea surface temperature distribution in the region between $10^{\circ} \mathrm{S}$ and $10^{\circ} \mathrm{N}$ from $160^{\circ}$ to $100^{\circ} \mathrm{W}$. The contour interval is $0.5^{\circ} \mathrm{C}$.

$2^{\circ} \mathrm{S}$ and $2^{\circ} \mathrm{N}$. In order to assess the possibility of a large frontal instability farther off the equator, we examined SST distributions from June 1990 to May 1991 using the Reynolds and Smith (1994) SST fields. (Fig. 22 shows an example of weekly mean SST in June and September 1990 and January 1991.) It is found that the meridional SST gradient is relatively large from June to September 1990, when the meridional shear related barotropic instability is strong; it is relatively small during the rest of the wave season and even smaller after the wave season. Thus, off-equator frontal instability may be occurring in concert with near-equator barotropic instability. In a recent study on equatorial zonal flow stability, Proehl (1996) suggested that the instability waves are generated by wave overreflection, with energy sources from the background current occurring through a mixture of baroclinic and barotropic instability. However, these TIWE data clearly show, near the equator, that barotropic instability is the only eddy energy source.

In summary, our results indicate that the tropical instability waves observed from August to December 1990 in the central equatorial Pacific Ocean were generated by barotropic instability arising from the cyclonic shear of mean zonal velocity component within the SEC and EUC just north of the equator. The instability waves were then maintained by this cyclonic shear instability, augmented and modulated by shear instability arising from the meridional gradient of mean meridional velocity component also just north of the equator, until the wave season terminated coincident with the passage of a large intraseasonal Kelvin wave. 
The main sink of wave energy is the meridional pressure work that radiates energy meridionally out of the generation region (although this effect may be offset by the zonal pressure work). Another important sink is the deformation work performed by the meridional gradient of mean meridional velocity component on and to the south of the equator. Three terms acting as smaller sinks of instability wave energy are the deformation work performed by the vertical shear of the zonal velocity component, the mean divergence of perturbation kinetic energy by the meridional velocity component fluctuation, and the conversion of kinetic to potential energy by the buoyancy force. The main result of barotropic production as a source and wave radiation via pressure work divergence as a sink are similar to the equatorial Atlantic findings of Weisberg and Weingartner (1988).

We emphasize that this energetics analysis is limited to the near-equator region at $140^{\circ} \mathrm{W}$. Since the waves tend to be more energetic farther east and baroclinic processes may be of increased importance away from the equator, both latitudinal and longitudinal variations of the wave energetics need further investigation, particularly the role of baroclinic sources/sinks within and across the frontal region north of the equator. The possible role of intraseasonal Kelvin waves in terminating the wave season by modifying of the background fields also warrants additional study.

Acknowledgments. Support was provided by the Ocean Science Division, National Science Foundation, Grant OCE-8813378 for the field work and OCE9302811 for the analyses.

\section{APPENDIX}

\section{Perturbation Energy Equations}

\section{a. The perturbation kinetic energy equation}

The PKE equation follows directly from the momentum equation, which in vector form is

$$
\mathbf{v}_{t}+(\mathbf{v} \cdot \boldsymbol{\nabla}) \mathbf{v}-f \mathbf{k} \times \mathbf{v}=-\frac{\boldsymbol{\nabla} p}{\rho}+\boldsymbol{\tau}_{z}-g \mathbf{k},
$$

where $\mathbf{v}$ is the velocity vector having components ( $u$, $v, w)$ in the conventional Cartesian coordinate system $(x, y, z)$ directed positive to the east, north, and up, respectively; $f$ is the Coriolis parameter; $p$ is pressure; $\rho$ is density; $\boldsymbol{\nabla}$ is a gradient operator; subscripted variables denote partial differentiation; $\boldsymbol{\tau}$ is the stress vector; $g$ is the acceleration or gravity; and $\mathbf{k}$ is the unit vector in the $z$ direction. Performing a Reynolds decomposition the perturbation momentum equation is

$$
\begin{aligned}
\mathbf{v}_{t}^{\prime} & +(\mathbf{V} \cdot \boldsymbol{\nabla}) \mathbf{v}^{\prime}+\left(\mathbf{v}^{\prime} \cdot \boldsymbol{\nabla}\right) \mathbf{V}+\left(\mathbf{v}^{\prime} \cdot \boldsymbol{\nabla}\right) \mathbf{v}^{\prime} \\
& -\left\langle\left(\mathbf{v}^{\prime} \cdot \boldsymbol{\nabla}\right) \mathbf{v}^{\prime}\right\rangle-f \mathbf{k} \times \mathbf{v}^{\prime}=-\left(\frac{\boldsymbol{\nabla} p}{\rho}\right)^{\prime}+\boldsymbol{\tau}_{z}^{\prime},
\end{aligned}
$$

where angle brackets denote an average over $500 \mathrm{~h}$, primes denote deviations of the individual variables about their 500-h averages, and capitalized variables are the 500-h running means. Since $\rho^{\prime}$ is much smaller than $\bar{\rho}$ (hereafter we replace $\langle\rho\rangle$ and $\langle p\rangle$ with $\bar{\rho}$ and $\bar{p}$, respectively, for convenience) the pressure gradient term in the above equation can be further developed as

$$
\begin{aligned}
\left(\frac{\nabla p}{\rho}\right)^{\prime} & =\left(\frac{\nabla \bar{p}+\nabla p^{\prime}}{\bar{\rho}+\rho^{\prime}}\right)^{\prime}=\left[\frac{1}{\bar{\rho}}\left(\frac{\nabla \bar{p}+\nabla p^{\prime}}{1+\rho^{\prime} / \bar{\rho}}\right)\right]^{\prime} \approx\left[\frac{1}{\bar{\rho}}\left(\nabla \bar{p}+\nabla p^{\prime}\right)\left(1-\rho^{\prime} / \bar{\rho}\right)\right]^{\prime} \\
& =\frac{1}{\bar{\rho}}\left[\nabla p^{\prime}-\nabla \bar{p} \rho^{\prime} / \bar{\rho}\right]=\frac{1}{\bar{\rho}}\left[p_{x}^{\prime} \mathbf{i}+p_{y}^{\prime} \mathbf{j}+p_{z}^{\prime} \mathbf{k}\right]-\frac{1}{\bar{\rho}^{2}}\left[\rho^{\prime} \bar{p}_{x} \mathbf{i}+\rho^{\prime} \bar{p}_{y} \mathbf{j}+\rho^{\prime} \bar{p}_{z} \mathbf{k}\right],
\end{aligned}
$$

where $(\mathbf{i}, \mathbf{j}, \mathbf{k})$ are the unit vectors of $(x, y, z)$. The hydrostatic approximation $0=-p_{z} / \rho-g$ gives

$$
D w / D t=D W / D t=D w^{\prime} / D t=0
$$

and consequently,

$$
\bar{p}_{z}=-\bar{\rho} g \quad \text { and } \quad p_{z}^{\prime}=-\rho^{\prime} g .
$$

Since the magnitudes of $\bar{\rho}_{x}$ and $\bar{\rho}_{y}$ will not be largely different from those of $\rho_{x}^{\prime}$ and $\rho_{y}^{\prime}$, the magnitudes of $\bar{p}_{x}$ and $\bar{p}_{y}$ will not be largely different from those of $p_{x}^{\prime}$ and $p_{y}^{\prime}$ as well. For $\rho^{\prime} / \bar{\rho}$ being at the order of $10^{-3}, \rho^{\prime} \bar{p}_{x} / \bar{\rho}^{2}$ and $\rho^{\prime} \bar{p}_{y} / \bar{\rho}^{2}$ will be much smaller than $p_{x}^{\prime} / \bar{\rho}$ and $p_{y}^{\prime} / \bar{\rho}$ and can be neglected. Thus,

$$
\left(\frac{\nabla p}{\rho}\right)^{\prime} \approx \frac{1}{\bar{\rho}}\left[p_{x}^{\prime} \mathbf{i}+p_{y}^{\prime} \mathbf{j}+p_{z}^{\prime} \mathbf{k}\right]-\frac{1}{\bar{\rho}^{2}} \rho^{\prime} \bar{p}_{z} \mathbf{k}
$$

Taking the dot product between the vector form of the perturbation momentum equation and $\mathbf{v}^{\prime}$ and then averaging over $500 \mathrm{~h}$ results in the perturbation kinetic energy equation:

$$
\begin{aligned}
\mathrm{PKE}_{t} & +\langle(\mathbf{V} \cdot \boldsymbol{\nabla}) \mathrm{PKE}\rangle+\bar{\rho}\left\langle\mathbf{v}^{\prime} \cdot\left(\mathbf{v}^{\prime} \cdot \boldsymbol{\nabla}\right) \mathbf{V}\right\rangle \\
+ & \bar{\rho}\left\langle\mathbf{v}^{\prime} \cdot\left(\mathbf{v}^{\prime} \cdot \nabla\right) \mathbf{v}^{\prime}\right\rangle \\
& =-\left[\left\langle\mathbf{v}^{\prime} \cdot \nabla p^{\prime}\right\rangle-\frac{1}{\bar{\rho}}\left\langle\rho^{\prime} \mathbf{v}^{\prime}\right\rangle \cdot \nabla \bar{p}\right]-\bar{\rho}\left\langle\mathbf{v}^{\prime} \cdot \boldsymbol{\tau}_{z}^{\prime}\right\rangle,
\end{aligned}
$$


where PKE $=\bar{\rho}\left\langle\mathbf{v}^{\prime} \cdot \mathbf{v}^{\prime}\right\rangle / 2$. Since $w^{\prime 2}$ is five orders of magnitude smaller than $u^{\prime 2}$ and $v^{\prime 2}$,

$$
\mathrm{PKE}=\bar{\rho}\left\langle\mathbf{v}^{\prime} \cdot \mathbf{v}^{\prime}\right\rangle / 2 \approx \bar{\rho}\left\langle u^{\prime 2}+v^{\prime 2}\right\rangle / 2 .
$$

The pressure work term can be further simplified as

$$
\begin{aligned}
& \bar{\rho}\left\langle\mathbf{v}^{\prime} \cdot\left(\frac{\nabla p}{\rho}\right)^{\prime}\right\rangle \\
& =\left[\left\langle u^{\prime} p_{x}^{\prime}\right\rangle+\left\langle v^{\prime} p_{y}^{\prime}\right\rangle+\left\langle w^{\prime} p_{z}^{\prime}\right\rangle\right]-\frac{1}{\bar{\rho}}\left\langle\rho^{\prime} w^{\prime}\right\rangle \bar{p}_{z} \\
& =\left[\left\langle u^{\prime} p_{x}^{\prime}\right\rangle+\left\langle v^{\prime} p_{y}^{\prime}\right\rangle+\left\langle w^{\prime} p_{z}^{\prime}\right\rangle\right]+g\left\langle\rho^{\prime} w^{\prime}\right\rangle .
\end{aligned}
$$

Thus, the pressure work includes two parts: the rate of work by the velocity vector against the pressure gradient, redistributing PKE spatially (the first three terms), and the rate of work by the vertical velocity component against buoyancy (the last term). The integration of the first three terms over the domain beyond which the instability waves are evanescent is zero; therefore, these terms redistribute energy within the region. To be consistent with previous studies, those terms hereafter will be referred to as the pressure work. The last term represents the energy conversion between PKE and PPE. Since this is the link between PKE and the density structure, it will be considered separately from the pressure work. Note that since

$$
\left\langle w^{\prime} p_{z}^{\prime}\right\rangle+g\left\langle\rho^{\prime} w^{\prime}\right\rangle=-\left\langle w^{\prime} \rho^{\prime}\right\rangle g+g\left\langle\rho^{\prime} w^{\prime}\right\rangle=0,
$$

the conversion of PKE from PPE is due to the pressure work by the vertical velocity component only. Removing the factor $\bar{\rho}$ by assuming a mean density that is constant at $\bar{\rho}=1 \mathrm{~g} \mathrm{~cm}^{-3}$ (Boussinesq approximation) and neglecting the stress term, the PKE equation may be rewritten as

$$
\begin{aligned}
(\mathrm{PKE})_{t}= & -(\mathrm{UPKE})_{x}-(\mathrm{VPKE})_{y}-(\mathrm{WPKE})_{z} \\
& -\left\langle u^{\prime} u^{\prime}\right\rangle U_{x}-\left\langle u^{\prime} v^{\prime}\right\rangle\left(U_{y}+V_{x}\right)-\left\langle v^{\prime} v^{\prime}\right\rangle V_{y} \\
& -\left\langle u^{\prime} w^{\prime}\right\rangle U_{z}-\left\langle v^{\prime} w^{\prime}\right\rangle V_{z}-\frac{1}{2}\left\langle\left(u^{\prime 2}+v^{\prime 2}\right) u^{\prime}\right\rangle_{x} \\
& -\frac{1}{2}\left\langle\left(u^{\prime 2}+v^{\prime 2}\right) v^{\prime}\right\rangle_{y}-\frac{1}{2}\left\langle\left(u^{\prime 2}+v^{\prime 2}\right) w^{\prime}\right\rangle_{z} \\
& \left.-\left(\left\langle p_{x}^{\prime} u^{\prime}\right\rangle+\left\langle p_{y}^{\prime} v^{\prime}\right\rangle+p_{z}^{\prime} w^{\prime}\right\rangle\right)+g\left\langle\rho^{\prime} w^{\prime}\right\rangle .
\end{aligned}
$$

\section{b. Perturbation potential energy equation}

The PPE equation follows from the perturbation density equation:

$$
\begin{aligned}
\rho_{t}^{\prime} & +\left(\mathbf{v}^{\prime} \cdot \boldsymbol{\nabla}\right) \rho^{\prime}+(\mathbf{V} \cdot \boldsymbol{\nabla}) \rho^{\prime}+\left(\mathbf{v}^{\prime} \cdot \boldsymbol{\nabla}\right) \bar{\rho} \\
& -\left\langle\left(\mathbf{v}^{\prime} \cdot \boldsymbol{\nabla}\right) \rho^{\prime}\right\rangle=0
\end{aligned}
$$

Taking the product of this equation with $\rho^{\prime}$ and averaging over $500 \mathrm{~h}$ yields

$$
\begin{aligned}
\rho^{\prime} \rho_{t}^{\prime} & +\rho^{\prime}\left(\mathbf{v}^{\prime} \cdot \nabla\right) \rho^{\prime}+\rho^{\prime}(\mathbf{V} \cdot \boldsymbol{\nabla}) \rho^{\prime}+\rho^{\prime}\left(\mathbf{v}^{\prime} \cdot \nabla\right) \bar{\rho} \\
& \left.-\rho^{\prime}\left\langle\left(\mathbf{v}^{\prime} \cdot \nabla\right) \rho^{\prime}\right\rangle\right] g / \bar{\rho}_{z}=0 .
\end{aligned}
$$

Defining PPE $=\frac{1}{2} g\left\langle\rho^{\prime 2}\right\rangle / \bar{\rho}_{z}$, then gives

$$
\begin{aligned}
(\mathrm{PPE})_{t} & +(\mathbf{V} \cdot \boldsymbol{\nabla}) \mathrm{PPE}+\frac{1}{2} g\left\langle\left(\mathbf{v}^{\prime} \cdot \boldsymbol{\nabla}\right) \rho^{\prime 2}\right\rangle / \bar{\rho}_{z} \\
& +g\left(\left\langle\rho^{\prime} \mathbf{v}^{\prime}\right\rangle \cdot \boldsymbol{\nabla}\right) \bar{\rho} / \bar{\rho}_{z}=0,
\end{aligned}
$$

or

$$
\begin{aligned}
(\mathrm{PPE})_{t}= & -U(\mathrm{PPE})_{x}-V(\mathrm{PPE})_{y}-W(\mathrm{PPE})_{z} \\
& -g\left(\bar{\rho}_{x}\left\langle\rho^{\prime} u^{\prime}\right\rangle-g \bar{\rho}_{y}\left\langle\rho^{\prime} v^{\prime}\right\rangle\right) / \bar{\rho}_{z}-\frac{1}{2} g\left(\left\langle\rho_{x}^{\prime 2} u^{\prime}\right\rangle\right. \\
& \left.+\left\langle\rho_{y}^{\prime 2} v^{\prime}\right\rangle+\left\langle\rho_{z}^{\prime 2} w^{\prime}\right\rangle\right) / \bar{\rho}_{z}-g\left\langle\rho^{\prime} w^{\prime}\right\rangle .
\end{aligned}
$$

\section{REFERENCES}

Cox, M., 1980: Generation and propagation of 30-day waves in a numerical model of the Pacific. J. Phys. Oceanogr., 10, 11681186.

Eliassen, A., and E. Palm, 1960: On the transfer of energy in stationary mountain waves. Geofys. Publ., 22 (3), 1-23.

Halpern, D., R. A. Knox, and D. S. Luther, 1988: Observations of 20-day period meridional current oscillations in the upper ocean along the Pacific equator. J. Phys. Oceanogr., 18, 1514-1534.

Hansen, D., and C. Paul, 1984: Genesis and effects of long waves in the equatorial Pacific. J. Geophys. Res., 89, 10 431-10 440.

Lukas, R., 1987: Horizontal Reynolds stresses in the central equatorial Pacific. J. Geophys. Res., 92, 9453-9463.

Luther, D. S., and E. S. Johnson, 1990: Eddy energetics in the upper equatorial Pacific during the Hawaii-to-Tahiti shuttle experiment, J. Phys. Oceanogr., 20, 913-944.

McCreary, J. P., and Z. Yu, 1992: Equatorial dynamics in a 21/2-layer model. Progress in Oceanography, Vol. 29, Pergamon, 61-132.

Philander, S. G. H., W. J. Hurlin, and R. C. Pacanowski, 1986: Properties of long equatorial waves in models of the seasonal cycle in tropical Atlantic and Pacific Oceans. J. Geophys. Res., 91, $14207-14211$.

Proehl, J. A., 1996: Linear stability of equatorial zonal flows. J. Phys. Oceanogr., 26, 601-621.

Qiao, L., and R. H. Weisberg, 1995: Tropical instability wave kinematics: Observations from the Tropical Instability Wave Experiment (TIWE). J. Geophys. Res., 100, 8677-8693.

— Undercurrent in the central Pacific. J. Phys. Oceanogr., 27, $1094-1119$

Reynolds, R. W., and T. M. Smith, 1994: Improved global sea surface temperature analysis using optimum interpretation. J. Climate, 7, 929-948.

Weisberg, R. H., 1984: Instability waves observed on the equator in the Atlantic Ocean during 1983. Geophys. Res. Lett., 11, 754756.

— , and T. J. Weingartner, 1988: Instability waves in the equatorial Atlantic Ocean. J. Phys. Oceanogr., 18, 1641-1657.

Wilson, D., and A. Leetmaa, 1988: Acoustic Doppler current profiling in the Equatorial Pacific in 1984. J. Geophys. Res., 93, 13 94713966.

Yu, Z., J. P. McCreary, and J. A. Proehl, 1995: Meridional asymmetry and energetics of tropical instability waves. J. Phys. Oceanogr., 25, 2997-3007. 